
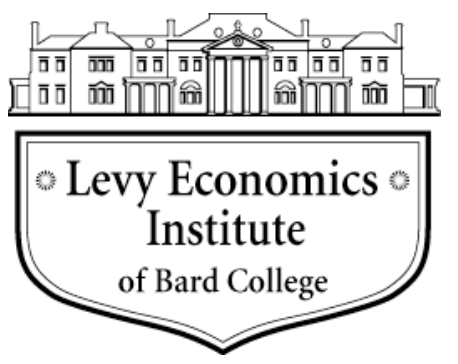

Working Paper No. 703

\title{
A Comparison of Inequality and Living Standards in Canada and the United States Using an Expanded Measure of Economic Well-Being
}

by

\author{
Edward N. Wolff, Ajit Zacharias, Thomas Masterson, and Selçuk Eren* \\ Levy Economics Institute of Bard College
}

Andrew Sharpe and Elspeth Hazell

Centre for the Study of Living Standards, Ottawa

January 2012

\begin{abstract}
* The research reported here was conducted as part of the Levy Institute's research project on international comparisons of economic well-being. Edward N. Wolff and Ajit Zacharias directed the project. We are grateful to the Alfred P. Sloan Foundation for their generous support. We are also grateful for the contributions of Benjamin Evans and Alexander Murray toward developing the estimates for Canada.
\end{abstract}

The Levy Economics Institute Working Paper Collection presents research in progress by Levy Institute scholars and conference participants. The purpose of the series is to disseminate ideas to and elicit comments from academics and professionals.

Levy Economics Institute of Bard College, founded in 1986, is a nonprofit, nonpartisan, independently funded research organization devoted to public service. Through scholarship and economic research it generates viable, effective public policy responses to important economic problems that profoundly affect the quality of life in the United States and abroad.

\author{
Levy Economics Institute \\ P.O. Box 5000 \\ Annandale-on-Hudson, NY 12504-5000 \\ http://www.levyinstitute.org
}

Copyright (C) Levy Economics Institute 2012 All rights reserved

ISSN 1547-366X 


\begin{abstract}
We use the Levy Institute Measure of Economic Well-being (LIMEW), the most comprehensive income measure available to date, to compare economic well-being in Canada and the United States in the first decade of the 21st century. This study represents the first international comparison based on LIMEW, which differs from the standard measure of gross money income (MI) in that it includes noncash government transfers, public consumption, income from wealth, and household production, and nets out all personal taxes.

We find that, relative to the United States, median equivalent LIMEW was 11 percent lower in Canada in 2000. By 2005, this gap had narrowed to 7 percent, while the difference in median equivalent MI was only 3 percent. Inequality was notably lower in Canada, with a Gini coefficient of 0.285 for equivalent LIMEW in 2005, compared to a US coefficient of 0.376-a gap that primarily reflects the greater importance of income from wealth in the States. However, the difference in Gini coefficients declined between 2000 and 2005. We also find that the elderly were better off relative to the nonelderly in the United States, but that high school graduates did better relative to college graduates in Canada.
\end{abstract}

Keywords: Well-Being; Living Standards; Inequality; Income; International Comparisons

JEL Classifications: D31, D63, P17 


\section{INTRODUCTION}

The picture of economic well-being is crucially dependent on the yardstick used to measure it. We develop a measure that is broader in scope than the standard measure of gross money income (MI) in that our measure includes noncash government benefits, public consumption, income from wealth, and household production, and nets out all personal taxes. The deficiencies of gross money income as measure of economic well-being have been widely acknowledged. The landmark report by the Canberra Group (2001), a group of international experts on household income statistics, recommended, among other things, that estimates of in-kind social benefits be added and the tax burden subtracted from money income to arrive at a better measure of household economic well-being.

MI seeks to estimate the command over marketed goods and services. Although commodities are of critical importance, they form only a portion of the entire set of goods and services available to households. The state plays a crucial role in the direct provisioning of the “necessaries and conveniences of life” (to use Adam Smith’s famous expression), such as public education and highways ("public consumption"). Nonmarket household work, such as childcare, cooking, and cleaning, also provides for necessaries and conveniences of life ("household production").

The Levy Institute Measure of Economic Well-Being (LIMEW) is a more comprehensive measure than MI. We generally follow the recommendations of the Canberra (2001) report, though we expand on their broader concept of income, as well. We include estimates of public consumption and household production in our measure, components that are excluded in most available measures of economic well-being. We also include estimates of long-run benefits from the ownership of wealth (other than homes) in the form of an imputed lifetime annuity — a procedure that, in our view, is superior to considering only current income from assets.

There are three key motivations behind constructing our broader measure. First, trends in well-being are sensitive to how we choose to measure well-being. A broader measure of wellbeing might be a better guide to actual differences in the standard of living across countries and over time. Second, in order to study disparities among key demographic groups, money income might give us only a partial picture of the relative well-being of one particular group compared to another. Third, our broader measure provides a more comprehensive measure of economic 
inequality. As one might expect, household production and public consumption are distributed much more equally than earnings among households. On the other hand, inequality in wealth is generally much higher than that of income or earnings. Our measure allows us to estimate the net effect of including these components.

The goal of this paper is to create and compare estimates of the LIMEW for Canada and the United States for comparable years. This paper represents the first such international comparison of well-being using our LIMEW index. The estimates for each country will be for around 2000 and 2005. We believe that the new results contained in this paper may force us to rethink the growth of well-being and trends in inequality among these two countries.

The story that unfolds is that there are some important similarities between Canada and the United States, but there are some striking disparities as well. There are three main factors that account for differences between the two countries. First, income from nonhome wealth is substantially higher as a share of LIMEW in the US. Second, household production played a larger role in LIMEW in Canada. Third, the inequality of base income (mainly labor earnings) was lower in Canada. Surprisingly, despite the more extensive welfare state in Canada, the fiscal system as a whole played little role in accounting for differences between the two countries. The reason is that while transfers and public consumption both played a larger role in Canada, these were offset by larger taxes in Canada.

The remainder of this paper is divided into six sections. The next section, Section 2, examines the recent literature comparing the economic well-being of Canada and the United States. Section 3 provides an overview of the components of LIMEW (see, e.g., Wolff and Zacharias 2007a, for more details). Two major components, income from wealth and net government expenditures, are examined, respectively, in Wolff and Zacharias (2007b) and Wolff and Zacharias (2009). Historical estimates of LIMEW for the US and detailed discussion of the empirical methodology can be found in Wolff, Zacharias, and Masterson (2009). Section 4 presents a comparison of overall well-being between Canada and the US. Section 5 presents a comparison between the two countries by demographic sub-group, including family type, age group, and educational group. Section 6 looks at economic inequality in the two countries. Concluding remarks are made in Section 7. The Appendix contains the details on the construction of LIMEW for the US and Canada (see, also, Sharpe et al. 2011). 


\section{LITERATURE REVIEW}

As Canada and the United States are both neighbors and close trading partners, the economic well-being of these countries is often compared. Not surprisingly, the conclusions drawn depend on the measure of economic well-being that is considered. Comparisons are usually conducted based on narrow income measures, such as earnings or disposable income, but increasingly more sophisticated measures are being developed and analyzed. These include composite measures of economic well-being such as the Human Development Index (HDI) and the Index of Economic Well-being (IEWB). The LIMEW fits in between these two types of measures, for although it does not capture all of the socioeconomic complexities portrayed in composite measures, it does describe a household's access to resources better than standard income measures because it includes a comprehensive measure of (imputed) income flows from wealth as well as public consumption and household production. Thus, it is useful to understand how Canada and the US compare in terms of these two measures.

Most studies find that Canadians are not only less rich, but also less unequal than their American neighbors. Wolfson and Murphy (1998) examine whether this is true by looking at the most narrow measures of economic well-being: earnings of individual workers and the disposable (after-tax) income of families. Their results indicated that American families (and workers) were better off than their Canadian counterparts, but inequality was sizably lower in Canada.

In an analysis of individual labor market outcomes, the authors found that these two nations experienced similar labor market trends between 1974 and 1995. Both countries saw large increases in the proportion of women in the labor force and in the average and median level of female earnings, while median earnings fell in both countries. One important difference, however, is that mean earnings in the United States were about the same in 1995 as in 1974, while mean earnings fell in Canada over this period. The inequality of earnings among male workers increased in both countries, but more sharply so in the US.

The pattern was slightly different for the distribution of disposable income among families. Their results showed that the inequality of disposable income fell in Canada from 1985 to 1995, but increased in the United States. Moreover, while the size of the middle class grew in Canada, it decreased in the US. 
In a later study, Foster and Wolfson (2010) also examined inequality of family disposable income in the United States and Canada in the 1980s. The authors concluded that inequality increased in the US from 1979 to 1986, while it decreased in Canada from 1981 to 1987.

In addition, Wolfson and Murphy (1998) found that in 1995, a large fraction of families in Canada were better off in absolute terms than families in the United States at similar positions in the income spectrum. The magnitude of this result, however, was sensitive to the measure used to equate the purchasing power of the Canadian and US dollar. When families were ranked lowest to highest by disposable income, and adjustments were made for family size, they found that the bottom 60 percent of Canadian families had greater purchasing power than their US counterparts on the basis of the Penn World Table's measure of purchasing power parity (PPP). In contrast, using Statistics Canada's measure, they found that only the bottom 35 percent of Canadian families was better off in terms of real disposable incomes than their US counterparts. In either case, a significant proportion of the Canadian poor were better off in absolute terms than their American peers. This is a surprising conclusion given that, on average, Americans are richer than their Canadian cousins.

A final observation made by Wolfson and Murphy (1998) was that the patterns in the Canadian and American labor markets were more similar from 1985 to 1995 than they were from 1974 to 1985, indicating some convergence in labor market trends. However, there was no convergence observed in the tax and social transfer policies of these two nations. Poor Canadians saw improvements in their economic situation, while poor Americans saw theirs deteriorate. On the other hand, the incomes of the richest Canadians did not grow as quickly as the average Canadian's from 1974 to 1995, while the richest American's income flourished in comparison to the average.

Beach, Finnie, and Gray (2010), in a more recent examination of inequality in women's and men's earnings in Canada, found that Canada's recent trends are close to those of the United States. The authors reported a rise in total earnings variance from 1982 to 2006, which was driven by a long-run increase in earnings inequality, particularly for men. A comparison with the US highlights the labor market similarities of these countries. In both countries, male permanent earnings inequality saw rapid increases in the late 1990s and early 2000s. Indeed, it was largely the increases in permanent earnings inequality that drove the increases in crosssectional earnings inequality for men in both countries, with the transitory instability of earnings 
contributing to a much lesser degree. Cross-sectional earnings inequality has also increased much less for women than for men since the late 1970s in both nations.

These findings are consistent with those of Heisz (2007), which is a report that examines income inequality and redistribution in Canada from 1976-2004. After adjusting for household size, Heisz (2007) found that market income showed increasing inequality throughout the entire period. In the 1980s, however, family disposable income inequality in Canada remained constant because the growth of public sector redistribution offset the increases in market income inequality. Although cash and noncash public sector transfers have offset increases in market income inequality in the United States, as well, the degree of offset was much lower in the US, and the US has had unrelenting increases in disposable income inequality since the late 1970s.

By the 1990s, however, redistribution could no longer keep pace with the increases in inequality from market income, and disposable income inequality began to grow in Canada. Heisz (2007) pointed out that slightly larger increases in disposable income inequality were observed in the United States than in Canada in the 1990s. However, just as in Canada, it was increases in market income inequality, not a reduction in public sector redistribution through taxes and transfers, which drove the disposable income inequality in the US. Moreover, although income taxes in both countries are progressive, the families in the lowest income group paid income taxes that amounted to a slightly larger proportion of their income in the US than they did in Canada in 1997-despite the fact that effective tax rates were, on the whole, lower in the US than they were in Canada (Wolfson and Murphy 2000).

Brandolini and Smeeding (2007) confirmed that, despite recent increases, Canada has a lower level of inequality than the United States. The difference between Canada and the US arises, in part, because public sector redistribution reduced Canada's market income inequality by more (28 percent) than it did in the US (23 percent).

The importance of the public sector is further emphasized when the value of noncash benefits (in-kind benefits) are included in the measure of disposable income. According to Garfinkel, Rainwater, and Smeeding (2006), English-speaking nations such as Canada and the United States had the largest reductions in inequality, as measured by the 90/10 ratio, when these benefits were included. This result reflects the relatively greater spending on noncash benefits by these nations and emphasizes the importance of examining noncash transfers in assessing income inequality in North America. 
In short, this brief survey yields the following conclusions. First, by the mid-1990s, inequality had reversed its earlier static or declining trend and had begun to increase in Canada. Second, inequality in disposable income has been increasing in the United States since the 1980s. Third, Canada has been and remains less unequal than the US. Fourth, the public sector played an important role in the redistribution of income in these two countries.

Although the narrow measures of income discussed so far provide valuable insights as to the relative economic well-being of Canada and the United States, they necessarily omit other dimensions of economic well-being, such as economic security and health. These other dimensions are often addressed by creating a composite index.

The most widely used one is the Human Development Index (HDI) published by the United Nations Development Programme (UNDP). This index is based on three variables-life expectancy, education, and per capita income-which are weighted equally. In the 2010 HDI rankings, the United States ranked $4^{\text {th }}$ and Canada ranked $8^{\text {th }}$ (UNDP 2010). Although Canada had a higher life expectancy and more years of schooling than the US did, the US had higher per capita income.

A more comprehensive composite measure is the Index of Economic Well-being (IEWB) published by the Centre for the Study of Living Standards (CSLS). This index is composed of four sub-indices: per-capita consumption, per-capita wealth, economic equality, and economic security. These four domains are designed to reflect the distribution of resources and the average ability to access them in both the present and the future (Osberg and Sharpe 2009). Equal weights are usually applied to all four components. In 2007, Canada had a higher overall IEWB score than the United States did because, though the US had higher scores in consumption and wealth per capita, Canada had higher index scores in economic equality and economic security. From 1999 to 2005, the time period under analysis for the LIMEW, both Canada and the US saw their IEWB scores increase. The growth was slightly greater in the US (1.33 percent per year) than it was in Canada (1.30 percent per year), although Canada still had a higher score than the US did in 2005 (0.551 versus 0.484$)$.

\section{COMPONENTS OF LIMEW}

LIMEW is constructed as the sum of the following four components (see Table 1): base money income; income from wealth; net government expenditures (both cash and noncash transfers and 
public consumption, net of taxes); and household production. We provide here a summary of the procedures used to construct LIMEW. ${ }^{1}$ Base money income is defined as gross money income less the sum of property income (interest, dividends, and rents), and private pension income and government cash transfers (e.g., Social Security benefits). Earnings make up the overwhelming portion of base money income. The remainder consists of interpersonal transfers, workers' compensation paid by the private sector, and other small items. We add the employer contributions for health insurance premiums to base money income to derive base income.

The second component is imputed income from the household's wealth holdings. MI includes interest, dividends, and rent. From our perspective, property income is an incomplete measure of the economic well-being derived from the ownership of assets. Owner-occupied housing yields services to their owners over many years, thereby freeing up resources otherwise spent on housing. Financial assets, can, under normal conditions, be a source of economic security in addition to property-type income.

We distinguish between home wealth and other wealth. Housing is a universal need and home ownership frees the owner from the obligation of paying rent, leaving an equivalent amount of resources for consumption and asset accumulation. Hence, benefits from owneroccupied housing are reckoned in terms of the replacement cost of the services derived from it (i.e., a rental equivalent). ${ }^{2}$ We estimate the benefits from nonhome wealth (including private pension wealth) $)^{3}$ using a lifetime annuity method. ${ }^{4}$ We calculate an annuity based on a given amount of wealth, an interest rate, and life expectancy. The annuity is the same for the remaining life of the wealth holder, and the terminal wealth is assumed to be zero (in the case of a couple, we use the higher life expectancy in the annuity formula). Moreover, in our method, we account for differences in portfolio composition across households. Instead of using a single interest rate for all assets, we use a weighted average of asset-specific and historic real rates of

\footnotetext{
${ }^{1}$ It should be noted that for compatibility with the Canadian LIMEW, we have altered the standard methodology that we have used in previous calculations of LIMEW for the United States. As a result, the estimates presented here for the US LIMEW differ from our earlier estimates (for example, in Wolff, Zacharias, and Masterson 2009).

${ }^{2}$ This is consistent with the approach adopted in the United States' national accounts.

${ }^{3}$ Private pension wealth is the sum of wealth associated with employer-provided defined-benefit and definedcontribution pension plans.

${ }^{4}$ This method gives a better indication of resource availability on a sustainable basis over the expected lifetime than the standard bond-coupon method. The latter simply applies a uniform interest rate to the value of nonhome wealth. It thereby assumes away differences in overall rates of return for individual households ascribable to differences in household portfolios. It also assumes that the amount of wealth remains unchanged over the expected (conditional) lifetime of the wealth holder.
} 
return, ${ }^{5}$ where the weights are the proportions of the different assets in a household's total wealth.

The third component is net government expenditures - the difference between government expenditures incurred on behalf of households and taxes paid by households. Our approach to determine expenditures and taxes is based on the social accounting approach (Hicks 1946; Lakin 2002: 43-46). Government expenditures included in LIMEW are cash transfers, noncash transfers, and public consumption. These expenditures, in general, are derived from the National Income and Product Accounts. Government cash transfers are treated as part of the money income of the recipients. In the case of government noncash transfers, our approach is to distribute the appropriate actual cost incurred by the government among recipients of the benefit. $^{6}$

A contrasting approach is the "fungible value" method used by the US Census Bureau to value medical benefits in its extended income measures. The fungible value method is based on the argument that the income value for the recipient of a given noncash transfer is, on average, less than the actual cost incurred by the government in providing that benefit (see, for example, Canberra Group 2001: 24, 65). This valuation method involves estimating how much the household could have paid for the medical benefit after meeting its expenditures on basic items such as food and clothing, with the maximum payment for the medical benefit set equal to the average cost incurred by the government. We elected not to use the fungible value approach because of its implication that recipients with income below the minimum threshold receive no benefit from the service (like health care). This implication is inconsistent with our goal of measuring the household's access to or command over products. Further, unlike the social accounting method, the fungible value method would not yield the actual total government expenditure when aggregated across recipients. Such a feature is incompatible with our goal of estimating net government expenditures using a consistent methodology.

The other type of government expenditure that we include in LIMEW is public consumption. We begin with a detailed functional classification of government expenditures. We then exclude certain items because they fail to satisfy the general criterion of increasing the

\footnotetext{
${ }^{5}$ The rate of return used in our procedure is real total return (the sum of the change in capital value and income from the asset, adjusted for inflation). For example, for stocks, the total real return would be the inflation-adjusted sum of the change in stock prices plus dividend yields.

${ }^{6}$ In the case of medical benefits, the relevant cost is the "insurance value" differentiated by risk classes.
} 
household's access to goods or services. These items generally form part of the social overhead (e.g., national defense) and do not provide for a market substitute. Other expenditures, such as transportation, are allocated only in part to households because part of the expenditure is also incurred on behalf of the business sector. The household sector's share in such expenditures can be estimated on the basis of information regarding its utilization (for example, miles driven by households and businesses). The remaining expenditures (such as health) are allocated fully to households.

In the second stage, the expenditures for each functional category are distributed among households. The distribution procedures we follow build on earlier studies employing the government cost approach (e.g., Ruggles and O’Higgins 1981). Some expenditures such as education, highways, and water and sewerage are distributed on the basis of estimated patterns of utilization or consumption, while others such as public health, fire, and police are distributed equally among the relevant population.

The third part of net government expenditures is taxes. Our objective is to determine the actual tax payments made by households. We do not consider tax incidence in our analysis. Our approach is consistent with the government cost approach. We align the aggregate taxes in the microdata with their counterparts in the National Income and Product Accounts (NIPA), as we did for government expenditures. We include only taxes paid directly by households, including federal and state personal income taxes, property taxes on owner-occupied housing, payroll taxes (employee portion), and consumption taxes. ${ }^{7}$ Taxes on corporate profits, on businessowned property, and on other businesses, as well as nontax payments, are not allocated to the household sector because they are paid directly by the business sector.

The fourth component of LIMEW is the imputed value of household production. Three broad categories of unpaid activities are included in the definition of household production: (1) core production activities, such as cooking and cleaning; (2) procurement activities, such as shopping for groceries and for clothing; and (3) care activities, such as caring for babies and reading to children. These activities are considered as "production," since they can be assigned, generally, to third parties apart from the person who performs them, although third parties are not always a substitute for the person, especially for the third activity.

\footnotetext{
${ }^{7}$ Consumption taxes were not aligned to national accounts because an estimate of aggregate consumption taxes paid by the household sector is not available.
} 
Our strategy for imputing the value of household production is to value the amount of time spent by individuals on the basis of its replacement cost, as indicated by the average earnings of domestic servants or household employees (Kuznets, Epstein, and Jenks 1941: 432433; Landefeld and McCulla 2000). Research suggests that there are significant differences among households in the quality and composition of the "outputs" of household production, as well as the efficiency of housework (National Research Council 2005: ch. 3). The differentials are correlated with household-level characteristics (such as wealth) and characteristics of household members (such as the influence of parental education on childrearing practices). Therefore, we modify the replacement-cost procedure and apply to the average replacement cost a discount or premium that depends on how the individual (whose time is being valued) ranks in terms of a performance index. Ideally, the performance index should account for all the factors relevant in determining differentials in household production and the weights of the factors should be derived from a full-fledged multivariate analysis. Given the absence of such research findings, we incorporated three key factors that affect efficiency and quality differentialshousehold income, educational attainment, and time availability—with equal weights attached to each.

\section{THE LEVEL OF WELL-BEING IN CANADA VERSUS THE UNITED STATES}

The benchmark years for Canada are 1999 and 2005, and those for the United States are 2000 and 2004. We refer to the comparisons between the US in 1999 and Canada in 2000 as comparisons “around 2000.” Analogously, the comparisons between the US in 2004 and Canada in 2005 are referred to as comparisons “around 2005.” The Canadian wealth concept includes a variable called “pension wealth.” This is a combination of two types of pension wealth: (1) defined contribution (DC) plans, in which individuals have actual retirement accounts such as 401(k) plans and Individual Retirement Accounts (IRAs), as in the US; and (2) defined benefit (DB) pension wealth, in which the formula used to compute the benefit accruing to individual workers at the time of retirement is based on years of service and earnings history. In the Canadian data, the two types of pension wealth cannot be separated. For comparability with the 
Canadian data, we have added a measure of DB pension wealth to the US data in 2000 and 2004 (see Wolff 2007, for example, for sources and methods for this estimation). ${ }^{8}$

\subsection{Level of Well-Being}

The picture of economic well-being differs substantially between LIMEW and MI. By construction, MI had values less than LIMEW (see Table 2). The median value of MI amounted to 58 percent of the median LIMEW for Canada and 60 percent for the United States around 2000. Median MI was 14 percent higher in the US than in Canada. However, by 2005 or so, median MI in the two countries were virtually at parity. Median LIMEW, on the other hand, was 10 percent higher in the US around 2000, and 9 percent higher around 2005. Thus, the gap in median LIMEW between the US and Canada was quite a bit less than that in median MI around 2000, but the reverse was true around 2005.

Table 2 also shows two alternative LIMEW indices. If we strip away household production from LIMEW, we arrive at a measure called post-fiscal income (PFI). This measure reflects the effect of net fiscal incidence in an accounting sense; that is, it includes as part of household income all government expenditures incurred on behalf of households (public consumption and transfers), and net of tax payments by households. Median PFI was 24 percent greater in the United States than in Canada around 2000, but dropped to 14 percent higher around 2005. The larger differential, compared to the LIMEW, reflects the greater importance of household production in Canada compared to the US.

The second alternative measure, called comprehensive disposable income (CDI), shows the effects of stripping away both household production and public consumption from LIMEW. This measure reflects market-based transactions. The differential is even greater than PFI-a ratio of 1.30 between Canada and the United States around 2000 and 1.17 around 2005-a reflection of the greater importance of public consumption in Canada vis-à-vis the US.

Addendum A of Table 2 shows total hours worked. By our calculations, the median Canadian household put in 7 percent less hours in total work than their American counterparts. The biggest difference around 2000 was in market work, where the median Canadian household worked 11 percent less than the median American household. There was virtually no difference in median hours spent in household production around 2000, but most of the difference around

\footnotetext{
${ }^{8}$ The inclusion of DB pension wealth in LIMEW is a new addition to our methodology (DB pension wealth was not included in our earlier estimates).
} 
2005 was due to household production: for American households, market work fell so that there was only six hours difference between the median American and Canadian household, while for Canada, household production fell dramatically, so that the median American household spent 13 percent more on household production around 2005. The net result of these shifts was that around 2005, the median American household spent 12 percent more time in overall work.

Figure 1 provides more details on time worked. Results are shown for mean annual hours worked by men and women separately. Around 2000, men and women both worked fewer total hours in Canada than in the United States - a 12 percent difference in each case. The biggest differential was in market work, where Canadian men worked 17 percent fewer hours than American men on average, and Canadian women 19 percent less than American women. Average hours spent in household production was also 5 percent less for Canadian men than American men and 7 percent less for Canadian women in comparison to American women. Total hours of work remained lower for the Canadians around 2005, too, by roughly the same extent as around 2000. However, there were some changes in the pattern of time allocation between market work and household production. The differential in market work between Canadian and American men was 14 percent (a 3 percentage point decline) and between Canadian and American women it was down to 13 percent (a 6 percentage point decline). Perhaps reflecting the greater allocation of time toward market work, the differential in the hours of household production between the two countries widened for both men and women: the average Canadian man spent 11 percent less than his American counterpart (an increase of 6 percentage points), while for Canadian women, the gap rose to 10 percent (an increase of 3 percentage points). The observed changes appear to be consistent with the trends in the unemployment rate. The unemployment rate in the US rose from 4.2 to 5.1 percent between 2000 and 2004, while the Canadians had the opposite experience of an improving labor market with the unemployment rate falling to 6.8 percent in 2005 from the level of 7.6 percent in 2000. ${ }^{9}$

Addendum B of Table 2 shows trends in the various measures of well-being in equivalent dollars (that is, adjusted for changes in family size and composition). ${ }^{10}$ There is a

\footnotetext{
${ }^{9}$ The data on the unemployment rates were taken from the International Financial Statistics Database, published by the International Monetary Fund.

${ }^{10}$ The equivalence scale used here is the three-parameter scale employed in the US Census Bureau's experimental poverty measures (Short 2001: A-2). The three parameters attempt to take into account the following features of household consumption: on average, children consume less than adults; consumption rises less than proportionately with household size; and the increase in household consumption is generally more when a child is added to a
} 
slight widening of the differential between the United States and Canada around 2000. The ratio of equivalent MI is 1.18 compared to 1.14 for unadjusted MI, while the difference in the ratio of median equivalent LIMEW and median LIMEW is not as large: 1.12 compared to 1.10, respectively. Around 2005 the ratios of equivalence-scale adjusted measures were hardly different from the ratios of the non-adjusted measures at all: 1.08 compared to 1.09 for LIMEW and 1.03 compared to 1.02 for MI. ${ }^{11}$

We also show differences in real per capita LIMEW and MI in Table 2, Addendum C. Here, differences are extremely marked, with the United States enjoying a 29 percent advantage in the former and 26 percent advantage in the latter relative to Canada around 2000. By 2005, these differences had shrunk significantly, to 18 percent for LIMEW and 8 percent for MI.

In Panel B of Table 2, we compute annual rates of growth of each of the components. Median MI and median LIMEW show quite different rates of change over the 2000-2004 period in the case of the United States. Indeed, median MI fell at an annual rate of 0.98 percent, while median LIMEW increased at an annual rate of 0.74 percent. In the case of Canada, the direction of change was the same, but the rate of change was quite different with the former, rising by 1.22 percent per year from 1999 to 2005, and the latter by 0.66 percent per year. Thus, while median MI increased in Canada over these years, median MI fell in the US. In contrast, median LIMEW increased a bit faster in the US compared to Canada. In the case of the US, median LIMEW grew faster than either PFI (0.35 percent per year) or CDI (0.12 percent per year). In contrast, in Canada, CDI recorded the highest growth rate, at 1.73 percent per year, followed by PFI at 1.62 percent per year and, lastly, LIMEW at 0.66 percent per year.

MI shows a lower (that is, more negative) rate of growth when an equivalence scale adjustment is applied in the case of the United States, while median equivalent MI grows faster in Canada. Median equivalent LIMEW also grew more slowly than median LIMEW in the US,

single-person family than when a child is added to a two-person family. Specifically, the scale sets the ratio of the scale for two adults and one adult to a fixed value of 1.41. For single-parent households, the formula is $(A+0.8+$ $0.5 C)^{0.7}$; and for all other households, the formula is $(A+0.5 C)^{0.7}$, where $A$ indicates the number of adults and $C$ indicates the number of children.

${ }^{11}$ The difference in the effect of equivalence scale adjustment on the comparisons around 2000 (slight widening) relative to the comparisons around 2005 (practically no difference) appears to be due to the change in the relative value of the equivalence scale between the two years. Around 2000, the average value of the Canadian scale was about 2 percent higher than in the US, while around 2005, the average values were practically identical in the two countries. 
while the reverse was true for Canada. Indeed, median equivalent LIMEW showed a higher rate of increase in Canada than in the US. ${ }^{12}$

By our calculations, there was a noticeable decline in median annual hours worked over the early 2000s in Canada, 0.92 percent per year, and a more moderate decline in the United States, 0.35 percent per year. In the American case, this decline was entirely driven by a sharp reduction in hours spent in the labor market, and hours of housework actually increased. In the Canadian case, there was no change in hours of market work and a sharp reduction in hours of housework.

Just for comparison, we also show trends in real per capita GDP, LIMEW, and MI over the same period in Table 2, Panel B, Addendum C. Between 2000 and 2004, real per capita GDP grew in the United States at an annual rate of 1.82 percent, more than 1.5 percentage points faster than real per capita LIMEW. Real MI per capita, on the other hand, contracted at an annual rate of 0.89 percent. In the case of Canada, the three measures showed similar rates of growth. GDP per capita grew at 1.9 percent per year, and LIMEW per capita grew at 1.6 percent per year, while MI per capita advanced by 2.0 percent per year from 1999 to 2005 . Thus, it appears that while the growth in personal economic well-being lagged behind macroeconomic performance in the US, the opposite was true in Canada.

\subsection{Composition of LIMEW}

The composition of LIMEW by income quintile for the two countries is shown in Table 3. Looking at the last row for each country, we see that LIMEW in the United States has a much higher share of income from wealth than does Canada in both periods-25.5 and 22.9 versus 15.6 and 17 percent. Correspondingly, the importance of household production is much greater in Canada - a 32.4 percent share versus a 21.0 percent share in the US around 2000, and 27.8 versus 21.4 percent around 2005. The share of base income is slightly higher in the US, and the share of net government expenditures is less around 2000, but roughly the same around 2005.

There are also differences across quintiles. We see that base income as a share of LIMEW rises slightly between the first and fourth quintile and then takes a sharp decline for the top quintile in the United States around 2000, while for Canada, the share is relatively constant for the first three quintiles and rises over the two highest. Around 2005, the share of base

\footnotetext{
${ }^{12}$ See note 11 above on the changes in the equivalence scale.
} 
income in US LIMEW is highest for the first and the fourth quintiles, while in Canada, base income's share falls from the first to the third quintile, then rises in the fourth and fifth again. In both countries around 2000, income from wealth rises with LIMEW quintile, but the increase is much sharper in the US, from a 9.3 percent share to a 39.5 percent share, than it is in Canada, from an 11.3 to an 18.8 percent share. Around 2005, all quintiles have lower shares of income from wealth in the US, while there has been a shift in Canada to a sharper rise in income from wealth share across quintiles, with the bottom two quintiles losing ground in terms of share of LIMEW, and the top two quintiles gaining.

Net government expenditures as a share of LIMEW decline across quintiles in both countries in both years. But in this case, the decrease is sharper in Canada, from 18.3 to -8.3 percent, than it is in the United States, from 15.3 to -7.9 percent around 2000. This implies that the fiscal system is more redistributive in Canada than it is in the US (see below). By 2005, shares of net government expenditures had increased across the board in both countries, although the gains were larger in the US, and the increases were larger for the upper four quintiles than for the bottom quintile in both countries. Household production as a share of LIMEW increased across LIMEW quintiles for both countries for both years, with the exception that the top quintile's share is dramatically lower than the fourth quintile's in the US and slightly lower for Canada in 2005. While the US saw increases in the share of household production in the bottom four quintiles in the early 2000s, and only a small drop in the top quintile, Canada experienced across-the-board decreases.

For the population as a whole, the most notable change in the United States during the early 2000s was that net government expenditures as a share of LIMEW rose by 3.6 percentage points. This was largely a reflection of the sharp rise in the federal government deficit over these years, as taxes plunged by \$1,291 in 2000 dollars (from an 18.0 to 16.4 percent share of LIMEW). ${ }^{13}$ The growth in net government expenditures was also facilitated by an equal boost in transfers and a smaller increase in public consumption. The income from wealth component, in contrast, fell by 2.7 percentage points. This movement largely reflected the downturn in financial markets of the early 2000s. The share of base income in LIMEW fell moderately, by 1.3 percentage points, while that of household production showed a small increase of 0.4 percentage points.

\footnotetext{
${ }^{13}$ All dollar values for the paper are in 2000 PPP dollars, unless otherwise noted.
} 
In contrast, in Canada, the share of base income in LIMEW rose by 1.7 percentage points between 1999 and 2005, and the share of income from wealth rose by 1.5 percentage points. The share of net government expenditures also showed a rise of 1.5 percentage points. These three increases were offset by a plunge in the share of household production in LIMEW of 4.6 percentage points, which largely reflected a decline in hours spent in housework.

Since the relative importance of individual components can vary across the distribution, it is also interesting to examine how the composition of the LIMEW has changed for households in different parts of the distribution. In the case of the United States, base income as a share of LIMEW declined among the middle three LIMEW quintiles, showed almost no change for the bottom, but rose for the top. This change was largely a reflection of the rising earnings inequality because the middle quintiles actually saw an absolute decline in their base income, the lowest quintile saw no change, and the top quintile experienced growth over these years. ${ }^{14}$ The share of income from wealth decreased among all quintiles but fell most sharply for the top because of the larger importance of this component among the rich. Net government's share in LIMEW rose across the board, but the rise was smallest for the bottom quintile. This change largely reflected the fact that tax cuts were higher for upper income groups. The share of household production in LIMEW increased among the bottom four quintiles, but fell for the top quintile, as time spent doing housework declined among higher income families.

In Canada, the pattern of change was substantially different. The share of base income in LIMEW increased for the bottom four quintiles, with the top quintile showing a slight decline. Unlike in the United States, there was growth in base income for the bottom 80 percent of the LIMEW distribution in Canada, while the growth in base income was slightly less than the growth in LIMEW for the top quintile in Canada. ${ }^{15}$ In contrast, the share of income from wealth in LIMEW declined for the bottom 60 percent, rose slightly for the fourth quintile, and increased dramatically for the top quintile. In fact, the bottom 40 percent suffered absolute declines in their income from wealth. The changes suggest a rise in wealth inequality over these years. The change in the share of net government expenditures was positive for all quintiles, while that of household production was negative across the board.

\footnotetext{
${ }^{14}$ The Gini coefficient for base money income rose from 0.546 to 0.555 between 2000 and 2004.

${ }^{15}$ In Canada, the Gini coefficient for base money income declined slightly from 0.558 to 0.556 between 1999 and 2005.
} 


\subsection{Sources of Growth of LIMEW}

Table 4 shows a more detailed breakdown of the components of mean LIMEW for the two countries. It is first of note that mean LIMEW was much higher in the United States in both periods, a ratio of 1.29 around 2000, and 1.22 around 2005. This compares to ratios of 1.26 and 1.11 in mean MI and 1.10 and 1.09 in median LIMEW. As might be apparent, these differences reflect the larger degree of inequality in the US compared to Canada. It is also of interest that while base income in PPP dollar terms was 38 (23) percent higher in the US than in Canada, income from nonhome wealth was over three (two) times higher in the US around 2000 (2005). The latter reflected the much higher holdings of nonhome wealth in the US. In contrast, income from home wealth was substantially lower in the US, a ratio of $0.72(0.64)$. In terms of net government expenditures, transfers were much lower in the US, a ratio of 0.79 (0.86), while taxes and public consumption were all slightly lower in the US. Household production was also 16 (6) percent lower in the US than in Canada.

In percentage terms, income from nonhome wealth as a share of LIMEW was much higher in the United States than Canada around 2000 (21.9 versus 9.2 percent), though the gap shrank by 2005 (to 19.8 versus 11.1), income from home wealth was much lower (3.6 versus 6.4 percent around 2000, 3.1 versus 6.0 percent around 2005), and transfers, public consumption, taxes, and household production were all higher in Canada (see Panel B of Table 4 and Figure 2). Also, as noted earlier, while base income and income from wealth-particularly nonhome wealth-declined as a share of LIMEW in the US from 2000 to 2004 and that of transfers and taxes became more positive, the share of base income and income from wealth in LIMEW rose in Canada from 1999 to 2005 and household production declined (Panel C).

Panel D shows the contribution to the overall change in mean LIMEW by component and country during the early 2000s (see also Figure 3). From 2000 to 2004 mean LIMEW grew by a meager 1.1 percent in the United States because of declines in base income and income from wealth. Of this increase, net government expenditures added 3.6 percentage points, while household production played a secondary role, with a contribution of 0.6 percentage points. In Canada, in contrast, mean LIMEW gained a robust 6.7 percent from 1999 to 2005. Of this increase, the biggest contributor by far was base income, which accounted for 5.1 percentage points of the overall rise. Income from wealth contributed another 2.6 percentage points and net government expenditures 1.7 percentage points, while household production subtracted 2.8 percentage points from the growth in LIMEW. 
As noted above, income from wealth was substantially higher in the United States. Some information on the factors behind the difference is provided in Table 5. The US had a lower income from home wealth in spite of its higher amount of home wealth. Gross home wealth was roughly 1.5 times higher, but imputed rent was 3 percent lower in the US, suggesting that the implicit rental rate on owner-occupied homes was much higher in Canada. On the other hand, the relatively higher amount of the annuitized value of mortgage debt in the US reflects the similarly higher level of debt itself (the US-to-Canada ratios for both the variables were in the range 1.93 to 2.00). The ratio of the annuitized value to the level of debt was almost identical in the two countries (around 5.5). Thus, the relatively lower income from home wealth in the US resulted from a combination of the lower rental rate and higher mortgage debt in the US.

The United States had a much higher income from nonhome wealth, reflecting mainly the higher amount of nonhome wealth held by American households, as noted above. However, the relatively higher effective rate of return on nonhome wealth also played a role in widening the gap in income from nonhome wealth in favor of the US. The gap in the rate of return was especially notable for pension assets, which constituted a much higher proportion of nonhome assets in Canada than in the US. Pension assets were less than a third of the nonhome assets in the US, while its share was roughly 50 percent in Canada.

It is quite likely that differences in the methodologies of the wealth surveys in the two countries also play a role in accounting for the observed outcomes. An important consideration here is the extent to which reliable information was collected from the "super-wealthy." The American wealth data is based on the Federal Reserve Board's Survey of Consumer Finances. Each survey consists of a core representative sample combined with a high-income supplement. The high-income supplement was selected as a list sample from statistical records (the Individual Tax File) derived from tax data by the Statistics of Income Division of the Internal Revenue Service (SOI). This second sample was designed to disproportionately select families that were likely to be relatively wealthy (see, for example, Kennickell 2001, for a more extended discussion of the design of the list sample in the 2001 SCF). In contrast, the Canadian wealth source, the Canadian Survey of Consumer Finances (SCF), while it does have some stratification by wealth, very likely does not capture the wealth holdings of the very rich as much as the US SCF. 
In contrast to income from wealth, the value of household production in LIMEW was lower in the United States than in Canada. The proximate factors behind the difference are shown in Table 6. The value of household production is the product of hours of household production and the implicit unit value. There is no explicit unit value for hours of household production at the household-level because, in general, the unit value of household production can differ among the individuals in a household. The valuation was done using the average wage of domestic workers, adjusted by an index that accounts for the differences among individuals in education, time availability, and household income (see Section 3). The average wage used in the calculations is shown in the table. We have also shown the value of household production that would have resulted if we were to use the average wage without any adjustment. The results indicate that the adjustment we made to the average wage had no effect on the ratio of the value of household production of one country to another around 2000, and only a minor effect around $2005 .^{16}$ The main factor behind the higher value of household production in Canada was the higher wage of domestic workers relative to the US. The catching up of the US seems to be mainly due to the rise in the relative wage of domestic workers, mirrored in the rising relative unit value of household production. The real hourly wage of domestic workers fell in Canada, from $\$ 9.20$ to $\$ 8.80$, while in the US it rose from $\$ 7.40$ to $\$ 7.70$ (all amounts are in PPP-adjusted 2000 international dollars). To a smaller extent, the narrowing was also due to the fact that the hours spent on household production went up in the US relative to Canada.

\subsection{The Middle Class}

We define the middle class as the middle quintile of the LIMEW distribution. The changes in the middle quintile's average is, in general, quite close to that in the overall median, and taking a closer look at the middle quintile can yield some insights into the factors behind the trends in well-being for the average household. There are some interesting contrasts between Canada and the United States. As shown in Figure 4, base income accounted for a larger share of LIMEW for the middle quintile in the US compared to in Canada, though there was some convergence in the early 2000s (57.4 versus 46.5 percent around 2000, 52.8 versus 48.3 percent around 2005). Overall income from wealth made up a larger share in Canada, with home wealth accounting for

\footnotetext{
${ }^{16}$ By construction, the composite index that we constructed to adjust the average wage has an average value of zero for individuals. However, this property will not carry over to households, as evidenced in the table by the discrepancy between the implicit unit value and the average wage.
} 
a larger share of LIMEW in Canada, and nonhome wealth contributing more in the US. Net government expenditures were more important in Canada around 2000 (7.7 versus 8.8 percent), but by 2005, the shares were roughly the same in the two countries. In both years, transfers and public consumption constituted a higher share of the LIMEW of the middle quintile in Canada, but taxes were also much higher than in the US. Household production, in contrast, played a bigger role in well-being in Canada than in the US around 2000, but this difference decreased substantially by around 2005 .

LIMEW of the middle quintile gained 3.0 percent in the United States from 2000 to 2004 (see Table 7 and Figure 5). By far, the main contributor was net government expenditures, which added 4.3 percentage points. Of this, 2.9 percentage points came from increased transfers, 0.7 percentage points from increased public consumption, and 0.7 percentage points from reduced taxes. Household production added another 2.4 percentage points. Of this, 31.5 percent came from increased hours of housework and 68.5 percent from an increased unit value of the time spent by the household on household production. In contrast, a decline in base incomereflecting falling real wages over the period-subtracted 3.0 percentage points, and declining income from wealth—mainly from home wealth—reduced it by another 0.6 percentage points.

In the case of Canada, LIMEW of the middle quintile grew by 4.4 percentage points from 1999 to 2005. Of this, 3.9 percentage points came from increased base income as real wages rose. Net government expenditures, mainly from rising transfers and public consumption, added another 3.2 percentage points. These rises were offset by a plunge in household production of 3.1 percentage points, 81.6 percent of which was due to a reduction in hours of housework and 18.4 percent from a reduction in the unit value of household production.

In sum, according to the LIMEW measure, the public sector was the leading source of middle class well-being growth between 2000 and 2004 in the United States, while the growth of base income (notably, labor earnings) and the public sector led the way in Canada from 1999 to 2005. 


\section{DEMOGRAPHIC DIFFERENCES IN ECONOMIC WELL-BEING}

We next look at disparities in well-being between population groups based on marital status, age of the householder, and education of the householder. ${ }^{17}$ We measure these by the ratio of mean values. $^{18}$

\subsection{Marital Status}

Both countries show a very high gap in LIMEW between families with a single-female householder ("single females”) and families with a married householder ("married couples")

(see Figure 6a). ${ }^{19}$ Around 2000, single females had an average LIMEW that was 62 percent that of married couples in the United States and 64 percent in Canada. Similar ratios held around 2005. In the US around 2000, single females had slightly less than half the base income of married couples, 39 percent the income from wealth, and 51 percent the level of household production. However, single females had 43 percent more on average in government transfers and 34 percent greater public consumption, and paid only 36 percent as much in taxes as married couples. By 2005, there was a shift from income from wealth to household production for female-headed households, as income from wealth dropped to 32 percent that of married couples, while household production rose to 57 percent.

In the case of Canada, the base income of single females averaged 42 percent that of married couples in 1999, income from wealth was 42 percent as well, and household production was 58 percent. On the other hand, as in the United States, transfers received by single females were higher (by 14 percent) than that of married couples, public consumption was 15 percent greater, and taxes paid were only 41 percent that of married couples. In contrast to the US, between 2000 and 2005, Canadian female-headed households gained on married couples in

\footnotetext{
${ }^{17}$ In the years prior to 1980 , the husband was always designated as the "head" or householder in married-couple families in the Census Bureau surveys in the United States. Since then, the householder is the person in whose name the housing unit is owned or rented. If it is owned or rented jointly by a married couple, then the householder may be either the wife or the husband.

${ }^{18}$ We prefer to use mean values, rather than medians, because it allows us to decompose the difference between subgroups into individual components. However, we will also note the ratio of median values when appropriate. ${ }^{19}$ We include only family households in this comparison, thus leaving out households with only one person and households with only unrelated individuals (e.g., roommates or unmarried partners). Also, due to space constraints, we have excluded single-male householders from the analysis.
} 
terms of base income, increasing to 48 percent, and decreased their relative household production to 56 percent, while losing only a little relative income from wealth.

Around 2000, the average LIMEW for single females was lower by $\$ 45,800$ in the United States as compared to married couples (see Figure 6b). The gap in base income was $\$ 34,100,74$ percent of the overall gap. The gap in income from wealth was less, $\$ 19,200$ or 42 percent of the overall gap. Further, the gap in home production was $\$ 13,900$ or 30 percent of the gap. On the other side of the ledger, married couples paid, on average, $\$ 14,400$ more in taxes than single females, and received \$3,500 less in the way of transfers and \$3,400 less in the way of public consumption. The total net government advantage for single females relative to married couples amounted to $\$ 21,400$. For Canada, the mean LIMEW for single females was lower by $\$ 32,500$. The difference in base income amounted to $\$ 27,600$ or 85 percent of the gap in LIMEW, much higher than in the US. The gap in income from wealth was correspondingly lower and accounted for 25 percent of the overall gap, which was much lower than in the US, while the difference in household production explained 40 percent of the overall gap. As in the US, transfers and public consumption were higher for single females and the tax burden lower, so that the overall gap in net government spending was $\$ 16,300$ in favor of single females.

By 2005, the gap in overall LIMEW was $\$ 700$ smaller in the United States and $\$ 1,100$ larger in Canada. In the US, the gap in base income increased by $\$ 500$, and in income from wealth by $\$ 300$. The advantage enjoyed by female-headed households in net government expenditures increased by $\$ 1,300$, while the gap in household production shrank by $\$ 2,800$. In Canada, the gap in base income fell by $\$ 500$, the gap in net government expenditures changed in female-headed households’ favor by $\$ 900$, but the gap in income from wealth increased by $\$ 2,400$.

Comparing the difference in LIMEW between single females and married couples in the two countries, we find that the gap in base income was $\$ 6,500(\$ 7,500)$, and that of income from wealth was $\$ 11,100$ (\$9,000) greater in the United States around 2000 (2005). However, the gap in government transfers in favor of single females was $\$ 2,000(\$ 2,700)$ greater in the US, that of public consumption $\$ 2,000(\$ 1,700)$ greater in US, and that of taxes paid was $\$ 1,100$ greater (\$1,500 smaller) in the US around 2000 (2005). All told, the gap in net government spending in favor of single females was \$5,100 (\$2,900) greater in the US around 2000 (2005).

There was no change in the ratio of LIMEW between single females and married couples in the United States over the period from 2000 to 2004. While base income, income 
from wealth, and transfers received by single females fell relative to married couples, and their relative tax burden increased, household production and public consumption of the former rose enough relative to married couples to offset these losses. In Canada, there was a small increase in the relative level of LIMEW of single females relative to married couples from 1999 to 2005.

\subsection{Age Group}

We next examine well-being for elderly versus nonelderly households. It is, at first, striking that according to LIMEW, the elderly were considerably better off than the nonelderly in the United States around 2000, a ratio of 1.08 (see Figure 7a). In contrast, in Canada, the LIMEW of the elderly averaged only 86 percent that of the nonelderly. Yet again, there was convergence between 2000 and 2005, as the US ratio dipped to 0.99 and the Canadian ratio rose to 0.91 .

In the United States, the elderly had 18 percent (20 percent) of the base income of the nonelderly but over three (two and a half) times the income from wealth, and 92 percent (90 percent) of household production around 2000 (2005). The elderly also had four to five times the amount of government transfers, but only about a third the level of public consumption, and paid only about 40 percent of the taxes of the nonelderly in the two years. The higher income from wealth of the elderly reflects the fact that the LIMEW includes the annuity value from nonhome wealth as income, which is quite high for the elderly, owing to a greater amount of accumulated wealth and a shorter remaining life expectancy. The greater transfers to the elderly reflect the large share of age-based entitlement programs (Social Security and Medicare) in total transfers. Taxes also fall much more on the nonelderly household than on the elderly because of the former's larger taxable income. ${ }^{20}$

In Canada, the elderly received one tenth of the base income of the nonelderly, had twice as much income from wealth, and 81 percent of the household production (rising to 91 percent in 2005). As in the United States, the elderly received much more in the way of government transfers, a ratio of 3.4, but had a lower relative level of public consumption (81 percent in 1999 and 79 percent in 2005). Their tax burden relative to the nonelderly was higher than in the US, a ratio of 55 percent in 1999, which fell to 51 percent in 2005.

Around 2000, the average LIMEW for the elderly in the United States was higher than it was for the nonelderly by $\$ 7,500$ (see Figure $7 \mathrm{~b}$ ). The gap in base income was $\$ 49,200$ in favor

\footnotetext{
${ }^{20}$ Most of Social Security income is excluded from taxable income.
} 
of the nonelderly, but the gap in income from wealth was $\$ 34,800$ in favor of the elderly, while the difference in home production was $\$ 1,500$ in favor of the nonelderly. The elderly received $\$ 18,000$ more in the way of government transfers than the nonelderly did, but received \$6,200 less in public consumption, and paid $\$ 11,700$ less in taxes. The total net government advantage for the elderly relative to the nonelderly amounted to $\$ 23,400$.

In Canada, the mean LIMEW of the elderly relative to the nonelderly was lower by $\$ 10,500$ around 2000 . The difference in base income amounted to $\$ 39,800$, lower than in the United States. The gap in income from wealth in favor of the elderly was $\$ 9,500$-much lower than in the US - while the difference in household production in favor of the nonelderly was $\$ 4,500$ - much higher than in the US. As in the US, transfers were much higher for the elderly than the nonelderly and public consumption less for the elderly (though the gap was much smaller than in the US). The gap in the taxes paid by the elderly relative to the nonelderly was also smaller than it was in the US, so that the overall gap in net government spending was $\$ 24,400$ in favor of the elderly, slightly higher than in the US.

Around 2005, the average LIMEW for the elderly in the United States was lower than it was for the nonelderly by $\$ 6,500$. The gap in base income fell to $\$ 47,100$ in favor of the nonelderly, but the gap in income from wealth declined to $\$ 25,600$ in favor of the elderly, while the difference in home production rose to \$2,000 in favor of the nonelderly. The elderly advantage in government transfers rose to $\$ 19,100$, but the gap in public consumption increased to $\$ 6,500$, and that of taxes fell to $\$ 9,800$ less in taxes. The total net government advantage for the elderly relative to the nonelderly shrank to $\$ 22,500$. In Canada, the gap in mean LIMEW between the elderly and the nonelderly fell to $\$ 7,300$ in 2005 . The difference in base income increased to $\$ 43,600$, closer to the gap in the US. The gap in income from wealth in favor of the elderly also grew to $\$ 11,800$, almost half that in the US, while the difference in household production in favor of the nonelderly fell to $\$ 2,000$, the same as in the US. The gaps in transfers and taxes both moved more in favor of the elderly to $\$ 18,800$ and $\$ 9,900$, respectively, while the gap in public consumption grew to $\$ 2,200$. The overall gap in net government spending increased to $\$ 26,500$ in favor of the elderly.

Comparing the disparity in LIMEW between the elderly and the nonelderly in the two countries, we find that the gap in base income in favor of the nonelderly was $\$ 9,300$ greater in the United States around 2000, but only \$3,500 greater around 2005 (see Figure 7b). The gap in income from wealth in favor of the elderly was $\$ 25,300$ greater in the US, but fell to $\$ 13,500$ 
around 2005, and the gap in government transfers in favor of the elderly was $\$ 600$ greater in the US, falling to $\$ 300$ around 2005. However, the disparity in public consumption in favor of the nonelderly was $\$ 4,500$ greater in the US (hardly changed at $\$ 4,300$ around 2005), and that of taxes paid was \$2,900 less in Canada around 2000, but slightly more in Canada around 2005. All told, the gap in net government spending in favor of the elderly was \$1,000 more in Canada, a very small difference around 2000, increasing to \$4,100 around 2005.

There was quite a drop in the ratio of LIMEW between elderly and nonelderly households in the United States over the period from 2000 to 2004 from 1.08 to 0.99. In contrast, the ratio increased in Canada from 0.86 to 0.91 from 1999 to 2005. In the US, the falling ratio could be traced primarily to a large reduction in the income from wealth (mainly from nonhome wealth) of the elderly relative to the nonelderly from a ratio of 3.09 to 2.56. A secondary contributor was a fall-off in the ratio of transfers received by the elderly relative to the nonelderly from 4.8 to 4.2. In the case of Canada, the improvement of the elderly relative to the nonelderly was due primarily to an increase in the ratio of income from wealth between the two groups from 2.00 to 2.08 and an increase in that of household production from 0.81 to 0.91 .

\subsection{Educational Group}

We next examine well-being by educational group based on the educational attainment of the householder. As shown in Figure 8a, gaps in well-being based on LIMEW by schooling group were larger in the United States than in Canada in dollar terms. The percentage gap relative to college graduates was also higher in the US than in Canada. Around 2000, the ratio of LIMEW for the least educated group relative to college graduates was 0.53 in the US, compared to 0.60 in Canada; the ratio between high school and college graduates was 0.64 in the US and 0.68 in Canada; and those between people with some college and college graduates were, respectively, 0.72 and 0.73 . By 2005 or so, the ratio for those without high school diplomas had dropped to 0.50 in the US, while in Canada it had risen to 0.64. The same divergence occurred for high school graduates, with the American ratio dropping to 0.63 and the Canadian ratio rising to 0.74, and also for those with some college, with the American ratio slipping to 0.70 and the Canadian ratio rising to 0.76 .

Some of the difference between the two countries can be traced to the steeper gradient of income from wealth of the lower educational groups relative to college graduates in the United States. In the US around 2000, the ratio with respect to the college-educated group increased 
from 0.41 for the least educated to 0.57 for high school graduates and 0.62 for those with some college, whereas in Canada, the ratios were all about 0.50. Similar patterns held around 2005. Average household production was also lower for less educated groups, but the gradient across education groups was similar in the two countries around 2000, with the ratios rising from 0.51 to 0.62 and then to 0.72 in the US, and from 0.57 to 0.67 and then to 0.74 in Canada. Results are similar around 2005.

Transfers received by the lowest education group were 2.9 times greater in the United States and 2.4 times greater in Canada than those received by college graduates around 2000, and 2.3 and 2.2 times greater, respectively, around 2005. Mean transfers for high school graduates were 83 percent greater than those for college graduates in the US and 40 percent more in Canada around 2000, and 64 and 50 percent more, respectively, around 2005. Transfers were 37 percent greater in the US and 24 percent greater in Canada for those with some college around 2000 compared to college graduates, and 26 and 24 percent greater, respectively, around 2005. Mean public consumption showed little variation across educational groups in both countries, though in the US, those with less than a college degree tended to receive more in public consumption, while those groups in Canada received less. The tax burden faced by less educated groups was lower than that for college graduates in both countries, but the gradient was once again steeper in the US, with the ratio of average taxes paid relative to college graduates rising from 0.20 to 0.37 and then to 0.52 in the US, and from 0.36 to 0.53 and then to 0.59 in Canada around 2000. Similar patterns existed for 2005.

Focusing on the differences between high school and college graduates, we find that around 2000, the average LIMEW of college graduates in the United States was higher than that of high school graduates by $\$ 45,800$. Most of this large difference was due to a gap in base income of $\$ 43,900$. The gap in income from wealth was less $(\$ 15,100)$ while the difference in household production was $\$ 10,300$. Offsetting these three components were higher transfers for high school graduates, a difference of $\$ 4,200$, and much lower taxes, a difference of $\$ 19,100$. The total net government advantage for high school graduates relative to college graduates amounted to $\$ 23,600$. By around 2005, the gap in LIMEW had increased to $\$ 48,300$. The greatest contributor was the decline in the gap in taxes, which shrank to $\$ 15,100$ in favor of high school graduates. The $\$ 1,000$ increase in the gap in income from wealth also contributed. These changes were offset by a $\$ 2,000$ drop in the gap in base income, which fell to $\$ 41,900$. 
In Canada, the mean LIMEW of high school graduates relative to college graduates was lower by $\$ 31,400$. The difference in base income amounted to $\$ 27,600$, lower than in the United States. The gap in income from wealth was $\$ 9,700$, much lower than in the US, while the difference in household production was $\$ 10,700$, about equal to the US. As in the US, transfers were higher for high school graduates and taxes paid were significantly less. The overall gap in net government spending was $\$ 16,600$ in favor of high school graduates, quite a bit lower than in the US. Unlike in the US, in Canada, the LIMEW gap shrank substantially by around 2005 to $\$ 25,900$. This was due mainly to the $\$ 8,700$ decline in the gap in income from wealth and the smaller \$1,200 increase in the advantage in transfers. Offsetting these gains were a \$3,000 increase in the gap in base income and a \$1,400 decline in the advantage enjoyed by high school graduates in taxes paid. The net impact of government expenditures was small, increasing the LIMEW gap by $\$ 500$.

Comparing the difference in LIMEW between high school and college graduates in the two countries around 2000, we find that the gap in LIMEW in favor of college graduates was $\$ 14,400$ greater in the United States (see Figure 8b). The gap in base income in favor of college graduates was \$16,300 greater in the US, 113 percent of the overall gap in LIMEW, while that of income from wealth was \$5,500 greater in the US, 38 percent of the overall LIMEW gap. The gap in government transfers in favor of high school graduates was \$1,400 greater in the US and that of taxes paid was $\$ 5,000$ greater in the US. All told, the gap in net government spending in favor of high school graduates was \$7,100 greater in the US. By around 2005, the difference in the gap had grown to $\$ 22,400$, as the gap grew by $\$ 2,500$ in the US and shrank by $\$ 5,500$ in Canada. This increase in the overall gap was due mainly to a huge increase in the gap in income from wealth between the two countries, which was partially offset by a decrease in the gap from base income between Canada and the US.

Overall educational differences in LIMEW widened slightly in the United States between 2000 and 2004. The ratio of LIMEW between the lowest educational group and college graduates fell by 3 percentage points, that between high school graduates and college graduates fell by one percentage point, and that between those with some college and college graduates declined by two percentage points. In contrast, in Canada, the differentials were actually reduced from 1999 to 2005, with the corresponding ratios increasing by 3, one, and 3 percentage points, respectively. In the US, the falling ratios could be traced mainly to widening gaps in income from wealth relative to college graduates and a fall-off in the ratio of transfers received 
by the less educated relative to college graduates. In the case of Canada, the improvement of the less educated relative to college graduates was due primarily to relative gains in income from both home and nonhome wealth of the less educated groups relative to college graduates.

\section{INEQUALITY}

We next look at trends in overall inequality. We begin our investigation with quintile shares (see Table 8). ${ }^{21}$ The share of total LIMEW received by the top (LIMEW) quintile in the United States was 48 percent around 2000, compared to only 40 percent in Canada. The shares of the bottom four quintiles were correspondingly lower in the US than in Canada. We also find greater inequality in the US in terms of MI quintiles, but the differences between Canada and the US are less marked than in the case of LIMEW. We also see a reduction of LIMEW inequality in the US from 2000 to 2004, with the share of the top quintile falling by 0.9 percentage points and that of the middle three quintiles gaining. In Canada, in contrast, the share of the top quintile increased by 1.3 percentage points from 1999 to 2005, while those of the bottom three fell.

Gini coefficients for different measures of well-being are shown in Table 9. Around the year 2000, the Gini index for LIMEW was 42.6 in the United States, but only 34.0 in Canadaan 8.6 point difference. The Gini coefficient in both countries rises when household production is subtracted from LIMEW to yield PFI, reflecting the equalizing effects of household production, and rises again when public consumption is deleted to yield CDI, since public consumption is distributed very progressively. However, differences in Gini coefficients for PFI and CDI between the US and Canada are even greater than those for LIMEW.

The Gini coefficient for MI is greater than that of LIMEW in both countries. Compared to LIMEW, MI shows larger inequality because it is a pretax measure and also because it does not take into account government noncash transfers. Moreover, MI also excludes public consumption and household production, which are relatively equally distributed, and, hence, their inclusion in LIMEW lowers LIMEW inequality relative to MI inequality. However, with regard to MI, Canada once again shows lower inequality than the United States, though the

\footnotetext{
${ }^{21}$ The quintiles of each income measure are defined by ranking households according to that measure. Therefore, in general, a given quintile of the different measures need not be made up of the same households.
} 
difference in Gini coefficients for MI between the two countries, 5.0 points, is lower than the gap in Gini coefficients for LIMEW.

Table 9 also shows Gini coefficients for equivalence scale adjusted measures of LIMEW and MI. The effect of the adjustment is to lower measured inequality in both measures. This is not surprising in light of the well-known positive correlation that exists between household size and income. The bottom rungs of the income distribution tend to have more single-person households and smaller families than the higher rungs. Additionally, in the case of LIMEW, public consumption and household production display strong positive correlation with household size. Consider, for example, households with school-age children. The single largest component of public consumption is public education, for which we have imputed per-pupil expenditures as a part of LIMEW. As a result, households with more school-age children would, in general, have a higher level of public consumption from educational expenditures. Similarly, hours spent on household production also tend to increase with the number of children at home, thus producing a positive correlation between household size and value of household production. $^{22}$

The inequality of equivalent LIMEW shows a much greater difference between the two countries, 12.0 Gini points, than that of unadjusted LIMEW. Likewise, the differential in the Gini coefficient between the two countries for equivalent MI, 6.9 Gini points, is greater than that of unadjusted MI. Panel B of the table shows the same set of measures for family households only. ${ }^{23}$ As expected, measured inequality is lower for families than all households since single individuals are excluded. However, the difference in inequality between the United States and Canada is even more marked on the basis of these family-only measures than on the basis of those for all households.

Between 2000 and 2004, the Gini coefficient for LIMEW fell by 0.6 points in the United States and that for equivalent LIMEW by 1.0 points. In contrast, in Canada, the Gini coefficient of LIMEW rose by 1.7 points from 1999 to 2005 and that for equivalent LIMEW by 1.9 Gini points. MI shows a different pattern. For the US, the Gini coefficient for MI increased by 0.5 points and that for equivalent MI increased by 0.4 Gini points. The results are similar for

\footnotetext{
${ }^{22}$ A separate issue concerns the applicability of standard equivalence scales to income measures that include nonmarket components such as public consumption and household production. This is an area that requires further research.

${ }^{23}$ A family household is a household with at least one family. The Census Bureau defines "family" as a group of two or more persons living in the same household and related to each other by blood, marriage, or adoption.
} 
Canada, where the Gini index for MI and equivalent MI both show a 0.3 point increase. Other LIMEW measures show somewhat different patterns, particularly for the US. In the case of PFI, the Gini coefficient fell by 0.1 points in the US and increased by 2.0 points in Canada, while that for CDI recorded a 0.2 point increase in the US and a 1.7 point rise in Canada. Family household measures all showed increases in inequality greater than the corresponding household measure in the US, while in Canada they all showed increases comparable to those of the corresponding household measures.

Decomposition of inequality by income components (or sources) is a standard technique used to assess the amount of inequality accounted for by individual components of income. The decomposition results, while not suggesting causality, can serve as a rough guide to the inequality-enhancing or inequality-reducing effects of the constituent components of a measure. To assess the contribution of different components to the changes in inequality of LIMEW, we first decompose the Gini coefficient of LIMEW in a given year into the level of inequality accounted for by the component. The level of inequality accounted for by a component is the product of that component's concentration coefficient and its share in total income (Table 10, Panel A). ${ }^{24}$

The contribution of a component to the difference in the Gini coefficients between the two countries is then calculated as the difference between the amount of inequality accounted for by that component in Canada less that in the United States (Table 10, panel B).

The contribution of base money income to the level of LIMEW inequality is somewhat higher in the United States compared to Canada. The lower contribution in Canada reflected both its smaller share of base money income in LIMEW and its lower degree of inequality in the distribution of base money income across the LIMEW distribution. The contribution of income from nonhome wealth to the level of inequality was substantially higher in the US than in

\footnotetext{
${ }^{24}$ The concentration coefficient of an income source $j$, denoted as $C_{j}$ can be expressed as: $c_{j}=r_{j} g_{j}$, where $r_{j}=\operatorname{cov}\left(y_{j}, F\right) / \operatorname{cov}\left(y_{j}, F_{j}\right), g_{j}$ is the Gini coefficient of income source, $y_{j}$ is the amount of income from the income source, and $F_{j}$ and $F$ are the cumulative distributions of the income source and total income (Lerman and Yitzhaki 1985). Since the Gini of base income is identical in both LIMEW and MI by construction, the difference in its concentration coefficient is solely due to the difference in the "Gini correlation" between the two variables, $r_{j}$.
} 
Canada. Almost all of this could be attributed to the higher share of this component in LIMEW in the US than in Canada.

Base income and income from wealth contributed positively to the gap in LIMEW inequality between the United States and Canada. In contrast, net government expenditures had an almost neutral effect. In both countries, net government spending made a negative contribution to LIMEW inequality, but the contribution of this component was virtually identical in the two countries. This similarity was also true of the three sub-components of net government spending - transfers, public consumption, and taxes. The contribution of household production to LIMEW inequality was greater in Canada than in the US. This difference reflected mainly the larger share of household production in LIMEW in Canada than in the US (32 percent versus 21 percent).

Of the difference in the LIMEW Gini coefficient of 0.086 between the United States and Canada, by far the biggest contribution was made by income from nonhome wealth, 0.119 points. Base income contributed another 0.021 points to the gap. Offsetting these were household production, which subtracted 0.047 from the gap between the US and Canada, and net government spending, which subtracted a trivial 0.002 .

Corresponding calculations are also shown for MI. Of the 0.028 gap in the Gini coefficient for MI between the United States and Canada, base money income and transfers had small effects, while current pension income subtracted 0.047 from the gap and property income contributed 0.031 .

We now shift our focus from overall inequality to examine how Canadian households in the different deciles of the (LIMEW) distribution have fared relative to their American counterparts (see Figure 9). It is notable that unlike the Wolfson and Murphy (1998) finding for 1995, there was no cross-over point between the Canadian and American curves in either year. In fact, the Canadian curve lay fully below the American curve in each of the two years, though the Canadian curve was closer to the American curve in the later year. Of course, our data are for around 2000 and 2005, whereas the Wolfson and Murphy (1998) comparison was for 1995. Another difference is that we are comparing LIMEW in the two countries, whereas they looked at family disposable income differences. However, we both use the Penn World Table PPP for our comparisons.

We also find that the lead enjoyed by American households was "pro-rich" in both the years. It was not merely "pro-rich,” but "pro-very rich”. That is, the lead was much larger for 
the 9th and, particularly, the top deciles. ${ }^{25}$ The relatively less "pro-very rich" pattern in the later year was probably a result of the losses suffered by the rich American households in their income from wealth, and also because of the growth in income from wealth for the rich Canadian households. We can also see that American households throughout the distribution lost their lead over Canadian households. It also appears that the relative reduction in the gap was higher for those in the upper portions of the distribution. This pattern is accounted for by the differences in income growth rates across the deciles. Growth in well-being favored the higher income groups more than the lower income groups in both countries. However, the Canadian pattern in growth rates was more “pro-rich” than that of the United States. The only group that suffered a notable absolute decline in their LIMEW was the top decile in the US.

\section{CONCLUSION}

There are some important similarities between Canada and the United States, but there are some striking dissimilarities, as well. There are three main factors that account for disparities between the two countries. First, income from nonhome wealth is substantially higher as a share of LIMEW in the US, though the difference declined somewhat over the first half of the decade of the 2000s. Second, household production played a larger role in LIMEW in Canada, though here, too, the difference declined over this time period. Third, the inequality of base income (mainly labor earnings) was lower in Canada, with virtually no change in the difference over these years. Surprisingly, despite the more extensive welfare state in Canada, net government expenditures were basically a wash in accounting for differences between the two countries. The reason is that while transfers and public consumption both played a larger role in Canada, these were offset by larger taxes in Canada.

With regard to dissimilarities in living standards, we do find that that median equivalent LIMEW was 8 percent higher in the United States than in Canada around 2005. However, this difference was more than fully accounted for by the greater hours worked in the US (12 percent higher at the median and 14 percent higher for the mean). Median equivalent LIMEW also grew faster in Canada than in the US over the first half of the decade of the 2000s — at annual rates of

\footnotetext{
25 The top decile in the United States had an average LIMEW that was double that of their Canadian counterpart in 2000 and about 75 percent higher in 2005.
} 
1.1 percent versus 0.6 percent—so that the gap in median equivalent LIMEW fell over these years.

Inequality was much greater in the United States than in Canada. Around 2005, the Gini index for LIMEW was 37.6 in the US, but only 28.5 in Canada—a 9.2 point difference. However, while the Gini index for equivalent LIMEW fell by 1.0 point in the US from 2000 to 2004, it increased by 1.9 points in Canada from 1999 to 2005, reducing the Gini index gap between the two countries from 12.0 to 9.2 points.

Of the difference in the (nonequivalent) LIMEW Gini coefficient of 0.086 between the United States and Canada in 2000, by far the biggest contribution was made by income from nonhome wealth, which contributed 0.114 to the gap. Base income also made a positive contribution of 0.021 points in around 2000. This result accords with previous findings of Wolfson and Murphy (1998) and Beach, Finnie, and Gray (2010) of higher earnings and labor market inequality in the US than in Canada.

Surprisingly, particularly in light of the preceding literature, net government expenditures contributed very little to the difference in inequality between the two countries. This result seems to conflict with the findings of Garfinkel, Rainwater, and Smeeding (2006), Heisz (2007), and Brandolini and Smeeding (2007). Garfinkel, Rainwater, and Smeeding (2006), in particular, emphasizes the importance of noncash government transfers in reducing inequality in Canada vis-à-vis the United States. Like these authors, we do find that both transfers and public consumption are considerably larger as a share of total LIMEW in Canada than in the US. However, the same is true for total taxes paid, and this factor helps to offset the redistributive effect of transfers and public consumption.

Overall, LIMEW in the United States had a much higher share of income from wealth in 2000 than did Canada_-26 versus 16 percent. Correspondingly, the importance of household production was much greater in Canada - a 32 versus a 21 percent share in the US. The share of base income was somewhat higher in the US (53.6 versus 50.2 percent), while the share of net government expenditures was slightly larger in Canada (1.8 versus - 0.1 percent).

The most notable change in the U.S during the early 2000s was that net government expenditures as a share of LIMEW rose by 3.6 percentage points. The income from wealth component, on the other hand, fell by 2.7 percentage points, reflecting the bust in financial markets of the early 2000s. In contrast, in Canada, the share of base income in LIMEW rose by 1.7 percentage points between 1999 and 2005, and that of both income from wealth and net 
government expenditure rose by 1.5 percentage points. These increases were offset by a plunge in the share of household production in LIMEW of 4.6 percentage points, which largely reflected a decline in hours spent in housework.

It is somewhat surprising that around 2005, at least, the share of net government spending in LIMEW was about the same in Canada and the United States (around 3.4 percent). This result seems to conflict with the earlier literature on US-Canada comparisons (see above). However, as noted above, the reason is that while both transfers and public consumption (particularly the former) make up higher shares of LIMEW in Canada than in the US, the share of total taxes in LIMEW is also considerably higher.

From 2000 to 2004 mean LIMEW in the United States grew by a meager 1.1 percent because of declines in base income and income from wealth. However, net government expenditures added 3.6 percentage points. In Canada, in contrast, mean LIMEW gained a robust 6.7 percent from 1999 to 2005. Of this increase, the biggest contributor by far was base income which accounted for 5.1 percentage points of the overall rise. Income from wealth contributed another 2.6 percentage points, while household production subtracted 2.8 percentage points from the growth in LIMEW.

Base income was a much more important component of LIMEW for the middle quintile in the United States compared to Canada (57 versus 47 percent in around 2000). Overall, income from wealth made up about 12 percent of LIMEW in the US and 13 percent in Canada, but home wealth accounted for a substantially larger share of Canada's LIMEW than it did in the US. Net government expenditures played a slightly bigger role in well-being in Canada than in the US (8.8 versus 7.7 percent of LIMEW), and household production a much larger role (31.5 versus 23.3 percent of LIMEW).

LIMEW of the middle quintile increased 3.0 percent in the United States from 2000 to 2004. By far, the main contributor was net government expenditures, which added 4.3 percentage points. In contrast, a decline in base income, reflecting falling real wages over the period, subtracted 3.0 percentage points, and declining income from wealth, mainly from home wealth, reduced it by another 0.6 percentage points. In the case of Canada, LIMEW of the middle quintile grew by 4.4 percentage points from 1999 to 2005. Of this, 3.9 percentage points came from increased base income as real wages rose. This was offset by a plunge in household production of 3.1 percentage points. In sum, according to the LIMEW measure, the public sector was the leading source of the growth in middle class well-being between 2000 and 2004 
in the US, while the growth of base income (notably, labor earnings) and the public sector led the way in Canada from 1999 to 2005.

Around 2000, single females had an average LIMEW that was 62 percent that of married couples in the United States and 64 percent in Canada. There was virtually no change in the ratio of LIMEW between single females and married couples in the two countries during the early 2000s. According to LIMEW, the elderly were considerably better off than the nonelderly around 2000 in the US, a ratio of 1.08. In contrast, in Canada, the LIMEW of the elderly averaged only 86 percent that of the nonelderly. There was quite a sharp drop in the ratio of the LIMEW between elderly and nonelderly households in the US over the period from 2000 to 2004 of 9 percentage points, whereas in Canada the ratio increased by 5 percentage points.

Gaps in well-being based on LIMEW by schooling group are higher in the United States than in Canada. Around 2000, the ratio of LIMEW for the least educated group relative to college graduates was 0.53 in the US, compared to 0.60 in Canada; the ratio between high school and college graduates was 0.64 in the US and 0.68 in Canada; and that between those with some college and college graduates was 0.72 in the US and 0.73 in Canada. Educational differences in LIMEW widened slightly in the US between 2000 and 2004, while in Canada, the differentials were actually reduced from 1999 to 2005. 


\section{REFERENCES}

Beach, Charles M., Ross Finnie and David Gray. 2010. "Long-Run Inequality and Short-Run Instability of Men's and Women's Earnings in Canada.” Review of Income and Wealth 56(3): 572-596.

Brandolini, Andrea and Timothy M. Smeeding. 2007. "Inequality Patterns in Western-Type Democracies: Cross-Country Differences and Time Changes.” Centre for Household, Income, Labour and Demographic Economics, No. 8. Turin, Italy.

Canberra Group. 2001. Expert Group on Household Income Statistics: Final Report and Recommendations. Ottawa: Canberra Group.

Foster, James E. and Michael C. Wolfson. 2010. "Polarization and the Decline of the Middle Class: Canada and the U.S.” Journal of Economic Inequality 8: 247-273.

Garfinkel, Irwin, Lee Rainwater and Timothy M. Smeeding. 2006. “A Re-examination of Welfare States and Inequality in Rich Nations: How In-Kind Transfers and Indirect Taxes Change the Story.” Journal of Policy Analysis and Management 25(4): 897-919.

Heisz, Andrew. 2007. “Income Inequality and Redistribution in Canada: 1976-2004.” Analytical Studies Branch Research Paper Series. Catalogue No. 11F0019MIE. No.298. May. Ottawa: Statistics Canada.

Hicks, Ursula K. 1946. “The Terminology of Tax Analysis.” The Economic Journal 56(221): 38-50.

Kennickell, Arthur B. 2001. "Modeling Wealth with Multiple Observations of Income: Redesign of the Sample for the 2001 Survey of Consumer Finances." October, http://www.federalreserve.gov/pubs/oss/oss2/method.html.

Kuznets, Simon S., Lillian Epstein, and Elizabeth Jenks. 1941. National Income and Its Composition, 1919-1938. New York: National Bureau of Economic Research.

Lakin, Caroline. 2002. "The Effects of Taxes and Benefits on Household Income, 2000-01.” Social Analysis and Reporting Division, Office for National Statistics, U. K. http://www.statistics.gov.uk/

Landefeld, J. Steven, and Stephanie H. McCulla. 2000. “Accounting for Nonmarket Household Production within a National Accounts Framework.” Review of Income and Wealth 46(3): 289-307.

Lerman, Robert I., and Shlomo Yitzhaki. 1985. "Income Inequality Effects by Income Source: A New Approach and Applications to the United States." Review of Economics and Statistics 67(1): 151-156. 
National Research Council. 2005. Beyond the Market: Designing Nonmarket Accounts for the United States. Panel to Study the Design of Nonmarket Accounts, K.G. Abraham and C. Mackie (eds.) Washington, DC: The National Academies Press.

Osberg, Lars and Andrew Sharpe. 2009. "New Estimates of the Index of Economic Well-being for Selected OECD Countries, 1980-2007.” Centre for the Study of Living Standards Research Report, No.11. Ottawa, Canada.

Ruggles, Patricia, and Michael O'Higgins. 1981. "The Distribution of Public Expenditure among Households in the United States." Review of Income and Wealth 27(2): 137-64.

Sharpe, Andrew, Alexander Murray, Benjamin Evans and Elspeth Hazell. 2011. The Levy Institute Measure of Economic Well-Being: Estimates for Canada, 1999 and 2005. Working Paper No. 680, July. Annandale-on-Hudson, N.Y.: Levy Economics Institute of Bard College.

Short, Kathleen. 2001. Experimental poverty measures 1999. Current Population Reports no. 216. Washington DC: U.S. Dept. of Commerce Economic and Statistics Administration Bureau of the Census.

UNDP (United Nations Development Programme)-Human Development Report Office. 2010. Human Development Reports 2010. New York: Palgrave Macmillan.

Wolff, Edward N. 2007. "The Retirement Wealth of the Baby Boom Generation.” Journal of Monetary Economics, 54(1), January: 1-40.

Wolff, Edward N., and Ajit Zacharias. 2007a. "The Levy Institute Measure of Economic WellBeing: United States, 1989 to 2001.” Eastern Economic Journal 33(4): 443-470. . 2007b. "The Distributional Consequences of Government Spending and Taxation in the U.S., 1989 and 2000.” Review of Income and Wealth 53(4): 692-715. . 2009. "Household Wealth and the Measurement of Economic Well-Being in the United States.” Journal of Economic Inequality, 7: 83-115.

Wolff, Edward N., Ajit Zacharias, and Thomas Masterson. 2009. "Long-Term Trends in the Levy Institute Measure of Economic Well-Being (LIMEW), United States, 1959-2004.” Working Paper No. 556, January. Annandale-on-Hudson, N.Y.: Levy Economics Institute of Bard College.

Wolfson, Michael and Brian B. Murphy. 1998. "New Views on Inequality Trends in Canada and the United States.” Monthly Labor Review 121(4): 3-23. . 2000. "Income Taxes in Canada and the United States." Perspectives. Catalogue No. 75-001-XPE, Summer. Ottawa: Statistics Canada. 


\section{TABLES}

Table 1 Components of LIMEW

\begin{tabular}{|l|}
\hline \multicolumn{1}{|c|}{ LIMEW } \\
\hline Money income (MI) \\
\hline Less: Property income, private pension income, and government cash transfers \\
\hline Equals: Base money income \\
\hline Plus: Employer contributions for health insurance \\
\hline Equals: Base income \\
\hline Plus: Income from wealth \\
\hline Annuity from nonhome wealth (including private pension wealth) \\
\hline Imputed rent on owner-occupied housing \\
\hline Less: Taxes $^{\text {Income taxes }}{ }^{1}$ \\
\hline Payroll taxes ${ }^{1}$ \\
\hline Property taxes ${ }^{1}$ \\
\hline Consumption taxes \\
\hline Plus: Cash transfers ${ }^{1}$ \\
\hline Plus: Noncash transfers \\
\hline Plus: Public consumption \\
\hline Plus: Household production \\
\hline Equals: LIMEW \\
\hline
\end{tabular}

Note:

(1) Aligned with the NIPA estimates.

(2) The government-cost approach is used. 
Table 2 Economic well-being and work, Canada and the US, around 2000 and 2005

A. Median values in 2000 constant PPP dollars ${ }^{1}$

\begin{tabular}{|l|r|r|r|r|}
\hline \multirow{2}{*}{ Levy measures } & \multicolumn{2}{|c|}{ US } & \multicolumn{2}{c|}{ Canada } \\
\cline { 2 - 5 } & $\mathbf{2 0 0 0}$ & $\mathbf{2 0 0 4}$ & $\mathbf{1 9 9 9}$ & $\mathbf{2 0 0 5}$ \\
\cline { 2 - 5 } & & & & \\
$\mathrm{PFI}^{2}$ & 69,514 & 71,599 & 63,350 & 65,902 \\
CDI $^{3}$ & 52,598 & 53,332 & 42,447 & 46,743 \\
Conventional measure & 43,754 & 43,971 & 33,784 & 37,438 \\
$\quad$ Money income (MI) & 42,000 & 40,370 & 36,686 & 39,451 \\
\hline Addendum A: Annual hours of work (median values) & & \\
Market work & 2,340 & 2,080 & 2,086 & 2,086 \\
Housework & 2,063 & 2,123 & 2,093 & 1,872 \\
Total & 4,749 & 4,683 & 4,429 & 4,189 \\
\hline Addendum B: Equivalence scale adjustment & & & \\
Equivalent LIMEW & 91,915 & 94,170 & 81,916 & 87,362 \\
Equivalent MI & 57,095 & 54,808 & 48,262 & 53,135 \\
\hline Addendum C: Real per capita amounts & & & \\
GDP & 35,051 & 37,666 & 27,286 & 30,591 \\
LIMEW & 35,799 & 36,077 & 27,690 & 30,472 \\
MI & 21,893 & 21,122 & 17,386 & 19,609 \\
\hline Addendum D: & 18.52 & 19.22 & 15.40 & 16.88 \\
\hline
\end{tabular}

B. Annual rate of change

\begin{tabular}{|c|c|c|}
\hline \multirow[b]{2}{*}{ Levy measures } & $\begin{array}{c}\text { US } \\
2000-04\end{array}$ & $\begin{array}{c}\text { Canada } \\
1999-2005\end{array}$ \\
\hline & & \\
\hline LIMEW & 0.74 & 0.66 \\
\hline $\mathrm{PFI}^{2}$ & 0.35 & 1.62 \\
\hline $\mathrm{CDI}^{3}$ & 0.12 & 1.73 \\
\hline Official measures & & \\
\hline Money income (MI) & -0.98 & 1.22 \\
\hline \multicolumn{3}{|c|}{ Addendum A: Annual hours of work (median values) } \\
\hline Market work & -2.90 & 0.00 \\
\hline Housework & 0.73 & -1.84 \\
\hline Total & -0.35 & -0.92 \\
\hline \multicolumn{3}{|c|}{ Addendum B: Equivalence scale adjustment } \\
\hline Equivalent LIMEW & 0.61 & 1.08 \\
\hline Equivalent MI & -1.02 & 1.62 \\
\hline \multicolumn{2}{|c|}{ Addendum C: Real per capita amounts } & \\
\hline $\mathrm{GDP}^{4}$ & 1.82 & 1.92 \\
\hline LIMEW & 0.19 & 1.61 \\
\hline $\mathrm{MI}$ & -0.89 & 2.03 \\
\hline $\begin{array}{l}\text { Addendum D: } \\
\text { LIMEW per hour of work }\end{array}$ & 2.79 & 1.54 \\
\hline
\end{tabular}

Notes:

(1) Purchasing power parities (PPPs) for actual individual consumption (2000 base year) from OECD.

(2) PFI equals LIMEW less the value of household production.

(3) CDI equals LIMEW less the value of household production and public consumption.

(4) GDP in 2000 constant PPPs from OECD.

Source: Authors' calculations 
Table 3 Composition of LIMEW by quintile, US and Canada

\begin{tabular}{|c|c|c|c|c|c|c|}
\hline Quintiles & \begin{tabular}{|c|} 
Mean LIMEW \\
(in 2000 PPP\$)
\end{tabular} & Total & $\begin{array}{c}\text { Base } \\
\text { income }\end{array}$ & \begin{tabular}{c|} 
Income \\
from wealth
\end{tabular} & \begin{tabular}{c|} 
Net \\
government \\
expenditures
\end{tabular} & $\begin{array}{l}\text { Household } \\
\text { production }\end{array}$ \\
\hline & \multicolumn{6}{|c|}{ US 2000} \\
\hline Lowest & 24,881 & 100 & 54.4 & 9.3 & 15.3 & 21.0 \\
\hline Second & 47,333 & 100 & 56.4 & 10.1 & 11.2 & 22.3 \\
\hline Third & 69,731 & 100 & 57.4 & 11.6 & 7.7 & 23.3 \\
\hline Fourth & 99,314 & 100 & 57.9 & 15.0 & 2.8 & 24.4 \\
\hline Highest & 225,741 & 100 & 49.8 & 39.5 & -7.9 & 18.5 \\
\hline \multirow[t]{2}{*}{ All } & 93,404 & 100 & 53.6 & 25.6 & -0.1 & 21.0 \\
\hline & \multicolumn{6}{|c|}{ US 2004} \\
\hline Lowest & 24,886 & 100 & 54.6 & 7.1 & 16.4 & 21.8 \\
\hline Second & 48,257 & 100 & 51.8 & 8.8 & 15.4 & 24.0 \\
\hline Third & 71,842 & 100 & 52.8 & 10.7 & 11.6 & 24.9 \\
\hline Fourth & 102,949 & 100 & 54.2 & 13.8 & 7.2 & 24.8 \\
\hline Highest & 224,108 & 100 & 51.1 & 35.7 & -4.9 & 18.1 \\
\hline \multirow[t]{2}{*}{ All } & 94,411 & 100 & 52.3 & 22.9 & 3.4 & 21.4 \\
\hline & \multicolumn{6}{|c|}{ Canada 1999} \\
\hline Lowest & 22,561 & 100 & 46.2 & 11.3 & 18.3 & 24.2 \\
\hline Second & 43,822 & 100 & 46.9 & 13.3 & 12.0 & 27.7 \\
\hline Third & 63,397 & 100 & 46.5 & 13.2 & 8.8 & 31.5 \\
\hline Fourth & 86,501 & 100 & 48.0 & 14.2 & 4.2 & 33.7 \\
\hline Highest & 144,983 & 100 & 54.7 & 18.8 & -8.3 & 34.7 \\
\hline \multirow[t]{2}{*}{ All } & 72,254 & 100 & 50.2 & 15.6 & 1.8 & 32.4 \\
\hline & \multicolumn{6}{|c|}{ Canada 2005} \\
\hline Lowest & 22,588 & 100 & 51.8 & 9.3 & 18.8 & 20.1 \\
\hline Second & 44,751 & 100 & 50.7 & 11.8 & 13.6 & 24.0 \\
\hline Third & 66,168 & 100 & 48.3 & 13.0 & 11.5 & 27.2 \\
\hline Fourth & 92,218 & 100 & 50.4 & 14.8 & 5.1 & 29.7 \\
\hline Highest & 159,632 & 100 & 54.5 & 22.6 & -6.2 & 29.0 \\
\hline All & 77,074 & 100 & 51.9 & 17.0 & 3.3 & 27.8 \\
\hline
\end{tabular}


Table 4 Composition of LIMEW

\section{A. Mean values in 2000 PPP dollars}

\begin{tabular}{|l|r|r|r|r|}
\hline & \multicolumn{2}{|c|}{ US } & \multicolumn{2}{c|}{ Canada } \\
\cline { 2 - 5 } Base Income & $\mathbf{2 0 0 0}$ & $\mathbf{2 0 0 4}$ & $\mathbf{1 9 9 9}$ & $\mathbf{2 0 0 5}$ \\
\cline { 2 - 5 } Income from wealth & 50,031 & 49,356 & 36,264 & 39,984 \\
Home wealth & 23,869 & 21,597 & 11,261 & 13,136 \\
Nonhome wealth & 3,392 & 2,928 & 4,628 & 4,594 \\
Net government expenditures & 20,474 & 18,666 & 6,633 & 8,542 \\
$\quad$ Transfers & -118 & 3,251 & 1,315 & 2,557 \\
Public consumption & 8,421 & 9,993 & 10,606 & 11,652 \\
Taxes & 8,242 & 8,749 & 8,473 & 9,306 \\
Household production & $-16,781$ & $-15,491$ & $-17,765$ & $-18,401$ \\
LIMEW & 19,623 & 20,207 & 23,415 & 21,397 \\
\hline Addendum: & 93,404 & 94,411 & 72,254 & 77,074 \\
Money Income & & & & \\
\end{tabular}

\section{B. Percent share}

\begin{tabular}{|l|r|r|r|r|}
\hline & \multicolumn{2}{|c|}{ US } & \multicolumn{2}{|c|}{ Canada } \\
\cline { 2 - 5 } Base Income & $\mathbf{2 0 0 0}$ & $\mathbf{2 0 0 4}$ & $\mathbf{1 9 9 9}$ & $\mathbf{2 0 0 5}$ \\
\cline { 2 - 5 } Income from wealth & 53.6 & 52.3 & 50.2 & 51.9 \\
Home wealth & 25.6 & 22.9 & 15.6 & 17.0 \\
Nonhome wealth & 3.6 & 3.1 & 6.4 & 6.0 \\
Net government expenditures & 21.9 & 19.8 & 9.2 & 11.1 \\
Transfers & -0.1 & 3.4 & 1.8 & 3.3 \\
Public consumption & 9.0 & 10.6 & 14.7 & 15.1 \\
Taxes & 8.8 & 9.3 & 11.7 & 12.1 \\
Household production & -18.0 & -16.4 & -24.6 & -23.9 \\
\hline
\end{tabular}

\section{Percentage point change in share}

\begin{tabular}{|l|c|c|}
\hline \multirow{4}{*}{ Base Income } & US & Canada \\
Income from wealth & -1.3 & 1.7 \\
Home wealth & -2.7 & 1.5 \\
Nonhome wealth & -0.5 & -0.4 \\
Net government expenditures & -2.1 & 1.9 \\
Transfers & 3.6 & 1.5 \\
Public consumption & 1.6 & 0.4 \\
Taxes & 0.4 & 0.3 \\
Household production & 1.6 & 0.7 \\
\hline
\end{tabular}

D. Contribution to Growth in LIMEW mean value by component (in percentage points)

\begin{tabular}{|l|c|c|}
\hline & US & Canada \\
Base Income & -0.7 & 5.1 \\
\cline { 2 - 3 } Income from wealth & -2.4 & 2.6 \\
Net government expenditures & 3.6 & 1.7 \\
Household production & 0.6 & -2.8 \\
\hline LIMEW & 1.1 & 6.7 \\
\hline
\end{tabular}


Table 5 Factors affecting income from wealth (mean values, 2000 PPP\$)

\begin{tabular}{|c|c|c|c|c|}
\hline \multirow[t]{2}{*}{ A. Flows } & \multicolumn{2}{|c|}{ US } & \multicolumn{2}{|c|}{ Canada } \\
\hline & 2000 & 2004 & 1999 & 2005 \\
\hline Income from wealth & 23,869 & 21,597 & 11,261 & 13,136 \\
\hline Home wealth & 3,392 & 2,928 & 4,628 & 4,594 \\
\hline Imputed rent & 5,561 & 5,891 & 5,750 & 6,082 \\
\hline Annuitized value of mortgage debt & 2,169 & 2,963 & 1,122 & 1,488 \\
\hline Nonhome wealth & 20,474 & 18,666 & 6,633 & 8,542 \\
\hline Annuitized value of nonhome assets & 20,995 & 19,321 & 7,193 & 9,387 \\
\hline Annuitized value of pension assets & 6,648 & 6,399 & 4,065 & 4,860 \\
\hline Annuitized value of other debt & 522 & 654 & 561 & 845 \\
\hline B. Stocks & \multicolumn{2}{|c|}{ US } & \multicolumn{2}{|c|}{ Canada } \\
\hline & 2000 & 2004 & 1999 & 2005 \\
\hline Net worth & 436,975 & 434,286 & 185,651 & 244,248 \\
\hline Home wealth & 75,535 & 100,637 & 54,648 & 76,542 \\
\hline Homes & 115,137 & 154,693 & 75,448 & 103,606 \\
\hline Mortgage debt & 39,602 & 54,057 & 20,800 & 27,064 \\
\hline Nonhome wealth & 361,441 & 333,649 & 131,003 & 167,705 \\
\hline Nonhome assets & 371,027 & 345,116 & 141,164 & 182,598 \\
\hline Pension assets & 110,465 & 104,957 & 76,304 & 88,974 \\
\hline Other debt & 9,587 & 11,467 & 10,160 & 14,893 \\
\hline \multirow[t]{2}{*}{ C. Flow-to-stock ratio (in percent) } & \multicolumn{2}{|c|}{ US } & \multicolumn{2}{|c|}{ Canada } \\
\hline & 2000 & 2004 & 1999 & 2005 \\
\hline Net worth & 5.5 & 5.0 & 6.1 & 5.4 \\
\hline Home wealth & 4.5 & 2.9 & 8.5 & 6.0 \\
\hline Homes & 4.8 & 3.8 & 7.6 & 5.9 \\
\hline Mortgage debt & 5.5 & 5.5 & 5.4 & 5.5 \\
\hline Nonhome wealth & 5.7 & 5.6 & 5.1 & 5.1 \\
\hline Nonhome assets & 5.7 & 5.6 & 5.1 & 5.1 \\
\hline Pension assets & 6.0 & 6.1 & 5.3 & 5.5 \\
\hline Other debt & 5.4 & 5.7 & 5.5 & 5.7 \\
\hline
\end{tabular}

Table 6 The valuation of household production (mean values, 2000 PPP\$)

\begin{tabular}{|l|l|r|r|r|r|r|}
\hline & & \multicolumn{1}{|l|}{ Hours } & \multicolumn{1}{l}{$\begin{array}{l}\text { Unit } \\
\text { value }\end{array}$} & \multicolumn{1}{|l|}{ Wage } & $\begin{array}{l}\text { Value of } \\
\text { household } \\
\text { production }\end{array}$ & $\begin{array}{l}\text { Alternative } \\
\text { value of } \\
\text { household } \\
\text { production }\end{array}$ \\
\hline \multirow{2}{*}{ Around 2000 } & Canada & 2,387 & 9.8 & 9.2 & 23,415 & 21,928 \\
\cline { 2 - 7 } & US & 2,486 & 7.9 & 7.4 & 19,623 & 18,434 \\
\hline \multirow{2}{*}{ Around 2005 } & Canada & 2,251 & 9.5 & 8.8 & 21,397 & 19,776 \\
\cline { 2 - 7 } & US & 2,364 & 8.2 & 7.7 & 19,457 & 18,298 \\
\hline \multirow{2}{*}{$\begin{array}{l}\text { US-to-Canada } \\
\text { ratio }\end{array}$} & $\begin{array}{l}\text { Around } \\
\mathbf{2 0 0 0}\end{array}$ & $104 \%$ & $80 \%$ & $81 \%$ & $84 \%$ & $84 \%$ \\
\cline { 2 - 7 } & $\begin{array}{l}\text { Around } \\
\mathbf{2 0 0 5}\end{array}$ & $105 \%$ & $87 \%$ & $88 \%$ & $91 \%$ & $93 \%$ \\
\hline
\end{tabular}

Note: (1) The alternative value of household production is the product of hours and wage. 
Table 7 Contribution of major components to the change in LIMEW of the middle quintile (percent)

\begin{tabular}{|c|c|c|c|c|}
\hline & \multicolumn{2}{|c|}{$\begin{array}{c}\text { United States } \\
2000-2004\end{array}$} & \multicolumn{2}{|c|}{$\begin{array}{c}\text { Canada } \\
1999-2005\end{array}$} \\
\hline & LIMEW & MI & LIMEW & MI \\
\hline Base Income & -3.0 & -4.1 & 3.9 & 5.6 \\
\hline Pension income (current) & & 0.5 & & 2.3 \\
\hline Income from wealth & -0.6 & -1.4 & 0.4 & -0.7 \\
\hline Home wealth & -0.7 & & -0.3 & \\
\hline Nonhome wealth & 0.1 & & 0.7 & \\
\hline Net government expenditures & 4.3 & 1.1 & 3.2 & 0.8 \\
\hline Transfers & 2.9 & 1.1 & 2.6 & 0.8 \\
\hline Public consumption & 0.7 & & 1.3 & \\
\hline Taxes & 0.7 & & -0.7 & \\
\hline Household production & 2.4 & & -3.1 & \\
\hline Total & 3.0 & -3.9 & 4.4 & 7.9 \\
\hline \multicolumn{5}{|c|}{ Addendum: Decomposition of the change in household production (in percent) } \\
\hline Total change & 100.0 & & 100.0 & \\
\hline Contribution to the change from: & & & & \\
\hline Change in hours & 31.5 & & 81.6 & \\
\hline Change in unit value & 68.5 & & 18.4 & \\
\hline
\end{tabular}

Notes:

(1) Middle class refers to the third quintile of the measure. The numbers shown in the line labeled

"Total" refers to the percent change in the third quintile's average between the two years.

(2) Contributions of individual components add up to the total.

(3) Unit value of household production equals total value of household production divided by total hours of household production.

(4) Base income in the money income definition does not include the health insurance premiums paid by the employer. 
Table 8 Quintile shares of LIMEW and MI, US and Canada

A. Quintile Shares

\begin{tabular}{|lrrrrr|}
\hline \multicolumn{7}{c|}{ Quintile } \\
\hline US 2000 & $\mathbf{1}$ & \multicolumn{5}{c|}{$\mathbf{3}$} & $\mathbf{4}$ & $\mathbf{5}$ \\
LIMEW & 5.3 & 10.1 & 14.9 & 21.3 & 48.3 \\
MI & 3.6 & 8.9 & 14.8 & 23.1 & 49.7 \\
US 2004 & & & & & \\
LIMEW & 5.3 & 10.2 & 15.2 & 21.8 & 47.5 \\
MI & 3.4 & 8.7 & 14.7 & 23.2 & 50.0 \\
Canada 1999 & & & & & \\
LIMEW & 6.2 & 12.1 & 17.5 & 23.9 & 40.1 \\
MI & 4.4 & 10.1 & 16.2 & 24.1 & 45.1 \\
Canada 2005 & & & & & \\
LIMEW & 5.9 & 11.6 & 17.2 & 23.9 & 41.4 \\
MI & 4.5 & 10.0 & 16.0 & 24.0 & 45.6 \\
\hline
\end{tabular}

Note: Quintiles for each income measure are defined with respect to that income measure. 
Table 9 Economic inequality by measure, US and Canada

I. Gini coefficient x 100

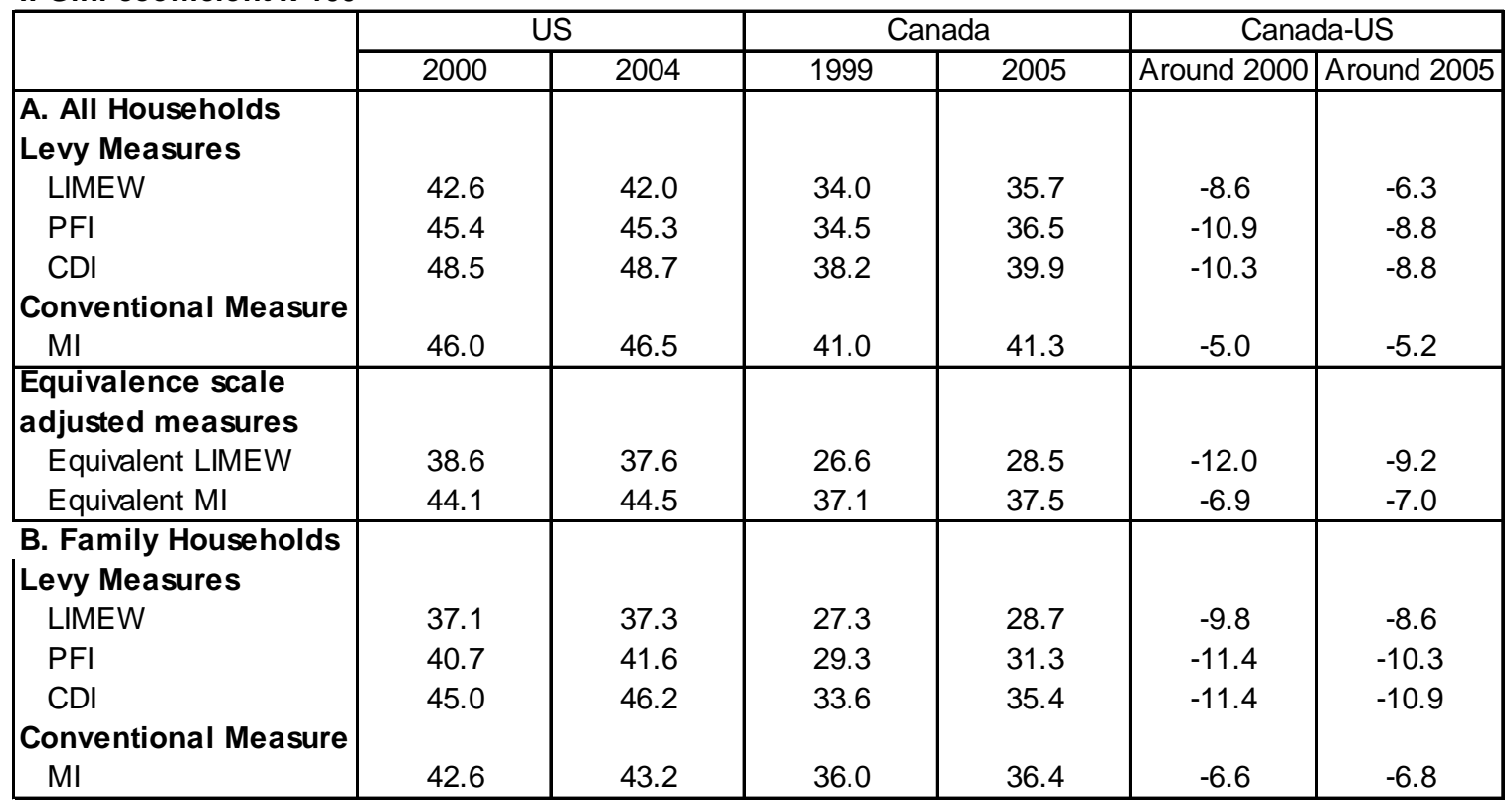

II Change in Gini coefficient x 100, U.S. and Canada

\begin{tabular}{|l|c|c|}
\cline { 2 - 3 } \multicolumn{1}{l|}{ A. All Households } & $\begin{array}{c}\text { US, 2000- } \\
\mathbf{2 0 0 4}\end{array}$ & $\begin{array}{c}\text { Canada, } \\
\text { 1999-2005 }\end{array}$ \\
\hline Levy Measures & & \\
LIMEW & -0.7 & 1.7 \\
PFI & -0.1 & 2.0 \\
CDI & 0.2 & 1.7 \\
Conventional Measure & & \\
$\quad$ MI & 0.5 & 0.3 \\
\hline Equivalence scale & & \\
adjusted measures & & 1.9 \\
$\quad$ Equivalent LIMEW & -1.0 & 0.3 \\
$\quad$ Equivalent MI & 0.4 & \\
\hline B. Family Households & & 1.4 \\
Levy Measures & & 2.0 \\
$\quad$ LIMEW & 0.2 & 1.7 \\
PFI & 0.9 & 0.4 \\
$\quad$ CDI & 1.2 & \\
Conventional Measure & & \\
$\quad$ MI & 0.6 & \\
\hline
\end{tabular}


Table 10 Decomposition of inequality by income source and income measure, US and Canada (Gini points x 100)

\begin{tabular}{|l|c|c|c|c|}
\cline { 2 - 5 } \multicolumn{1}{c|}{} & \multicolumn{2}{c|}{ US } & \multicolumn{2}{c|}{ Canada } \\
\cline { 2 - 5 } \multicolumn{1}{c|}{ LIMEW } & 2000 & 2004 & 1999 & 2005 \\
Base income & 21.0 & 21.2 & 18.9 & 19.5 \\
Income from wealth & 18.1 & 16.2 & 6.7 & 8.6 \\
Income from home wealth & 1.7 & 1.7 & 2.2 & 2.3 \\
Income from nonhome wealth & 16.4 & 14.5 & 4.4 & 6.3 \\
Net government expenditures & -4.3 & -2.9 & -4.2 & -3.4 \\
Transfers & 0.8 & 1.1 & 1.2 & 1.7 \\
Public consumption & 2.4 & 2.5 & 2.5 & 2.9 \\
Taxes & -7.5 & -6.6 & -7.9 & -8.0 \\
Household production & 7.8 & 7.5 & 12.6 & 11.0 \\
Total & 42.6 & 42.0 & 34.0 & 35.7 \\
Money Income & & & & \\
Base money income & 42.8 & 43.6 & 39.7 & 39.5 \\
Pension income (current) & 0.8 & 1.1 & 1.4 & 1.8 \\
Property income & 3.4 & 2.8 & 1.8 & 1.6 \\
Transfers & -1.0 & -1.0 & -1.9 & -1.5 \\
Total & 46.0 & 46.5 & 41.0 & 41.3 \\
\hline
\end{tabular}

\section{B. Contribution to the Difference in Inequality}

\begin{tabular}{|l|c|c|}
\cline { 2 - 3 } \multicolumn{1}{c|}{} & \multicolumn{2}{c|}{ Canada - US } \\
\hline \multirow{2}{*}{ LIMEW } & Around 2000 & Around 2005 \\
\cline { 2 - 3 } Base income & & \\
Income from wealth & -2.1 & -1.7 \\
$\quad$ Income from home wealth & -11.4 & -7.5 \\
Income from nonhome wealth & 0.5 & 0.6 \\
Net government expenditures & -11.9 & -8.2 \\
Transfers & 0.2 & -0.5 \\
Public consumption & 0.3 & 0.5 \\
Taxes & 0.2 & 0.4 \\
Household production & -0.3 & -1.4 \\
Total & 4.7 & 3.5 \\
Money Income & -8.6 & -6.3 \\
Base money income & & \\
Pension income (current) & -3.1 & -4.1 \\
Property income & 0.6 & 0.7 \\
Transfers & -1.7 & -1.2 \\
Total & -0.9 & -0.6 \\
\hline
\end{tabular}

Note: Contribution of each income source is expressed in Gini points multiplied by 100 . The numbers shown in the row labeled "Total" refer to the Gini ratio of the income measure 


\section{FIGURES}

Figure 1 Annual hours of total work, market work, and housework by sex (mean values, persons 19 years and older)

\section{A. Around 2000}

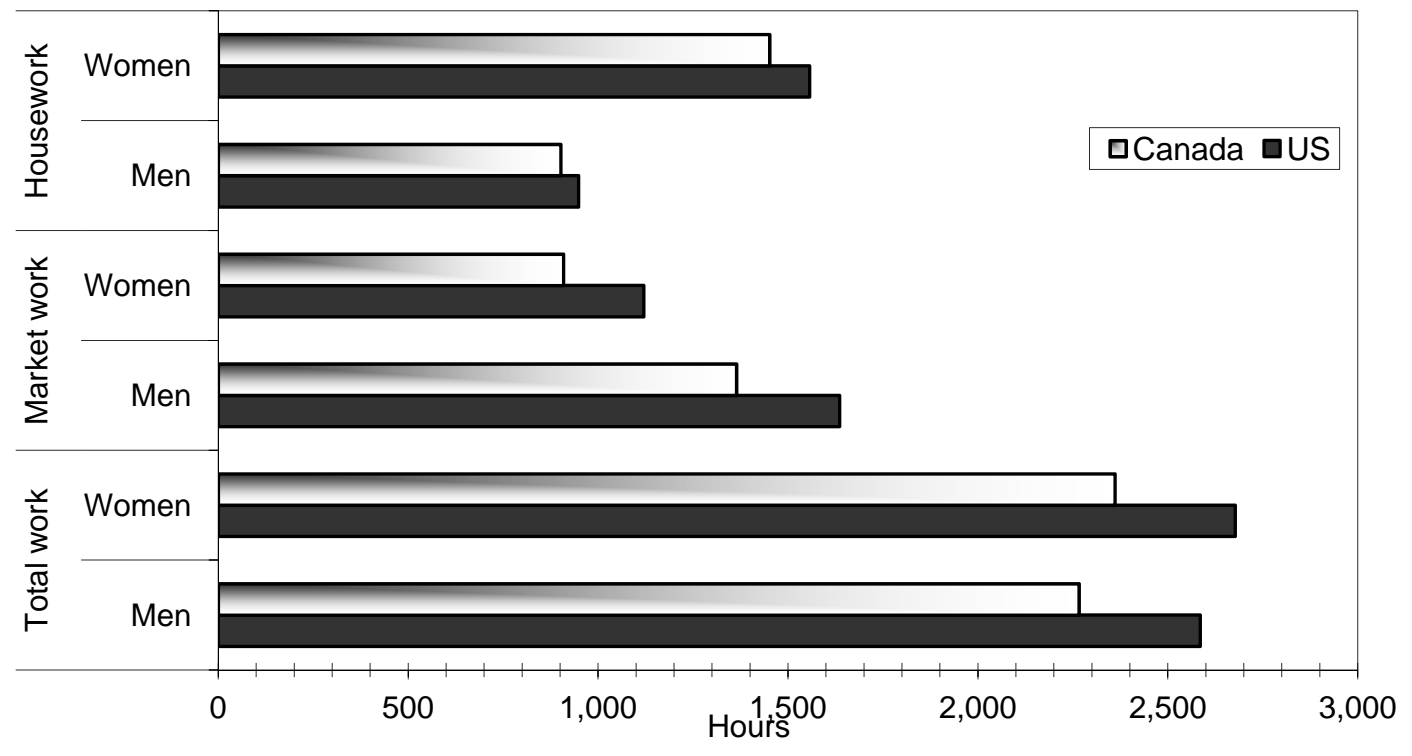

B. Around 2005

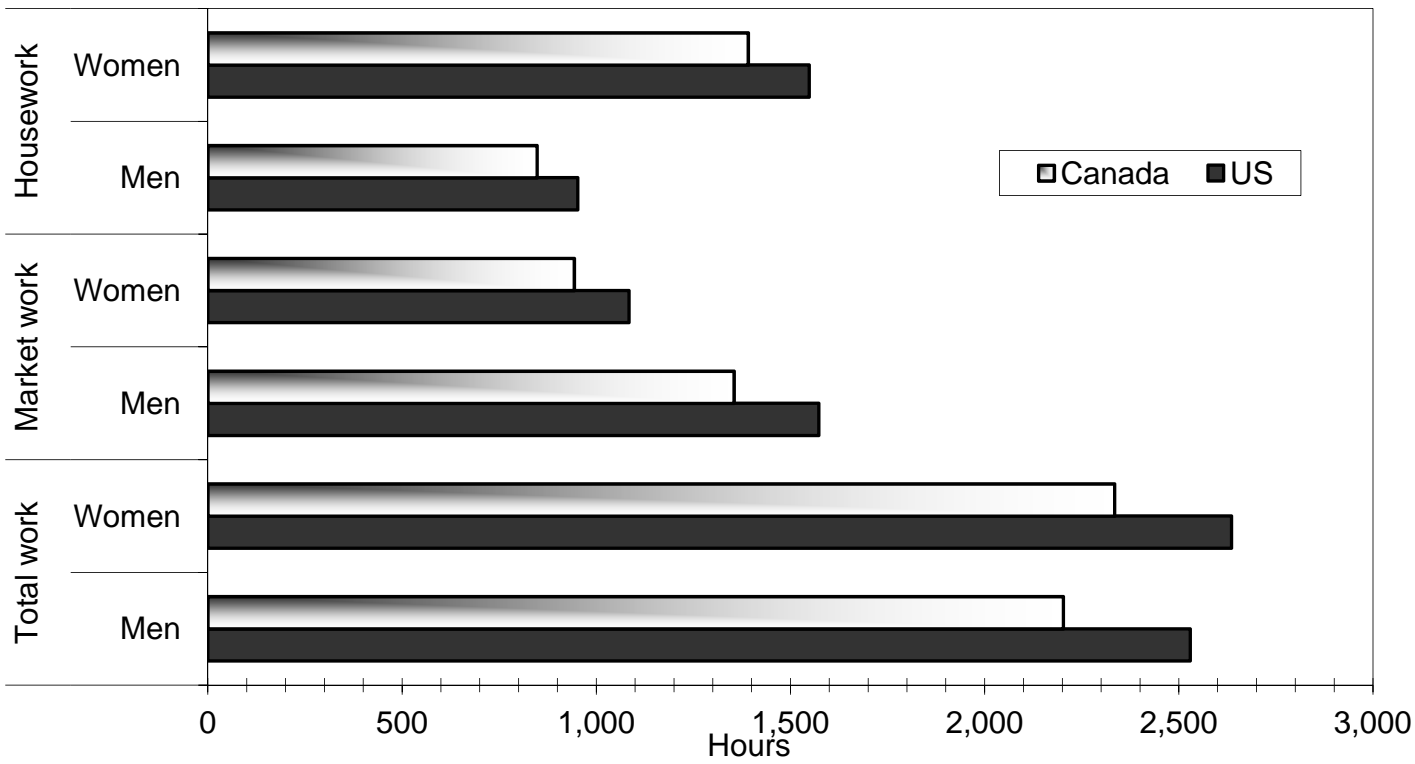


Figure 2 Composition of LIMEW by major component (percent)

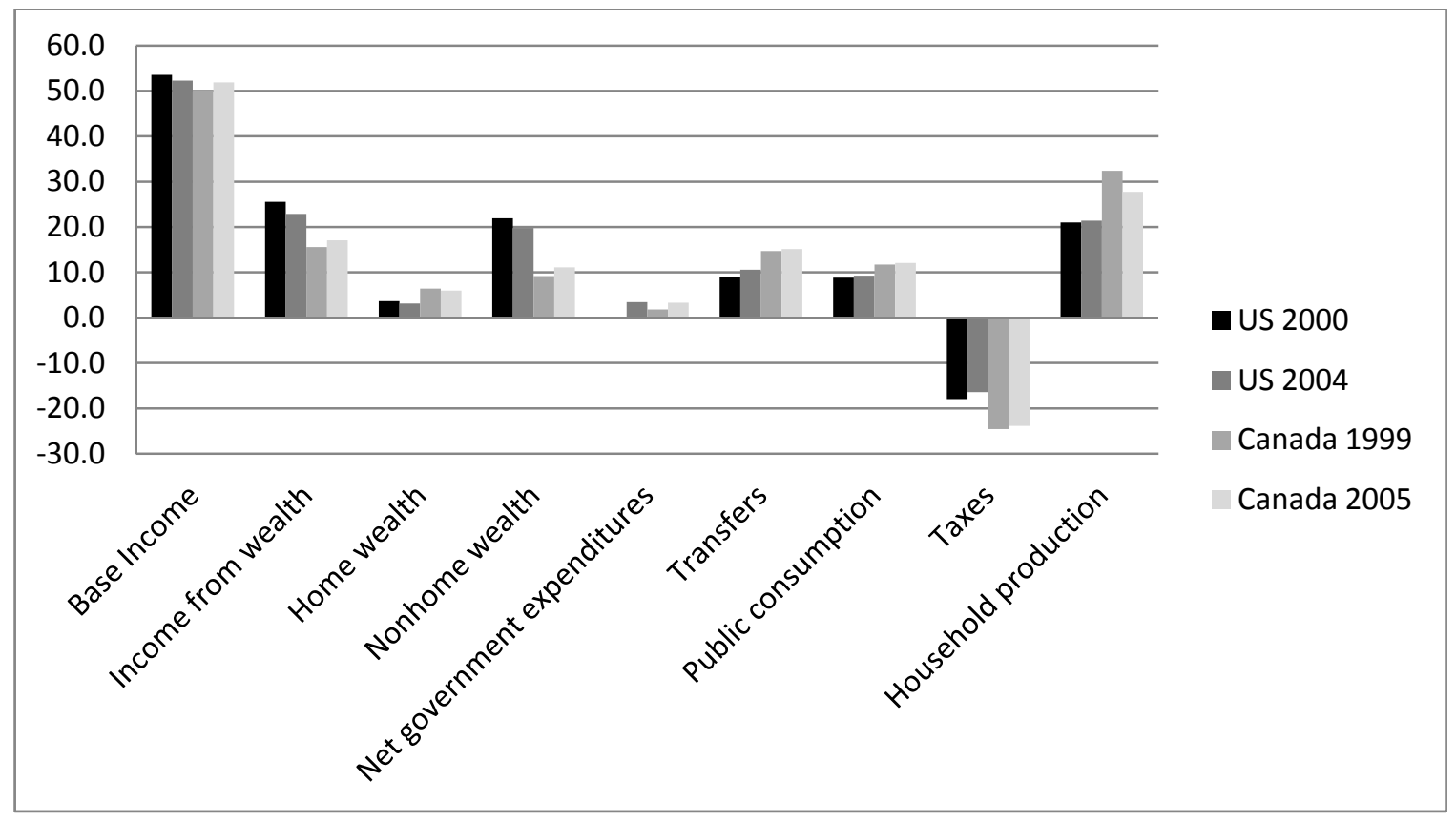

Figure 3 Contribution to the change in average LIMEW from each component (percentage point)

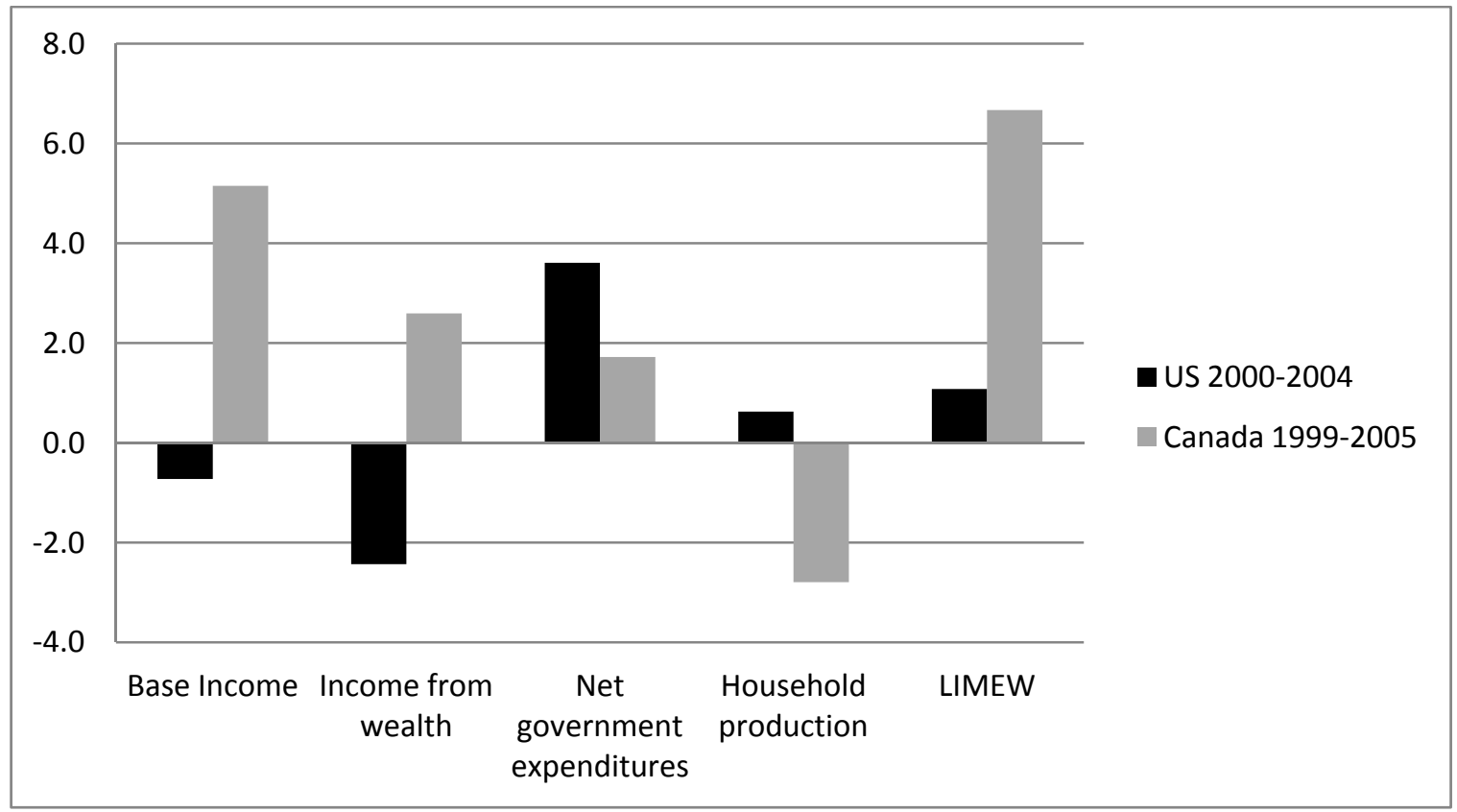


Figure 4 Composition of LIMEW of the middle quintile by major component (percent)

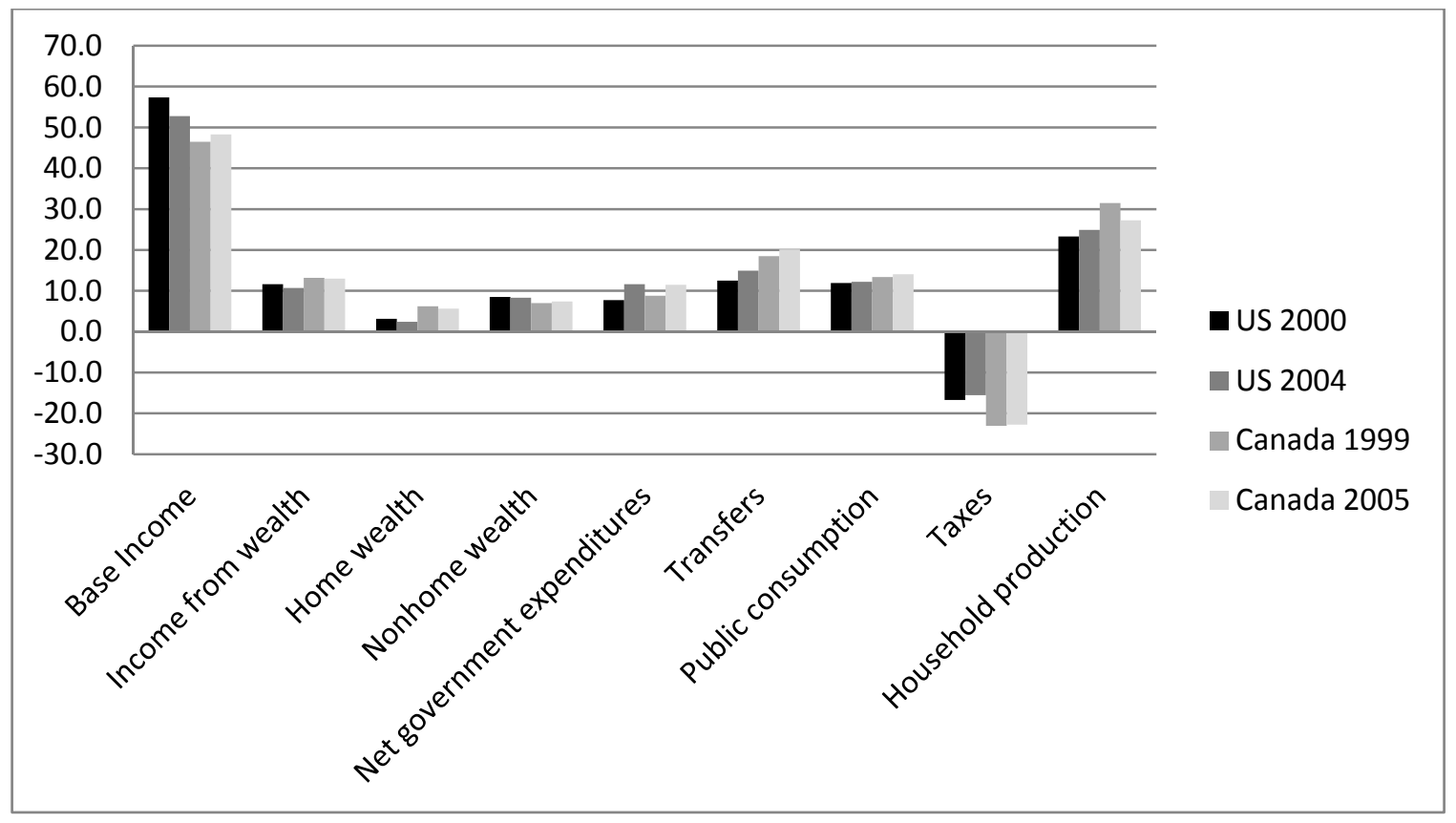

Figure 5 Contribution to the change in the average LIMEW of the middle quintile from each component (percentage point)

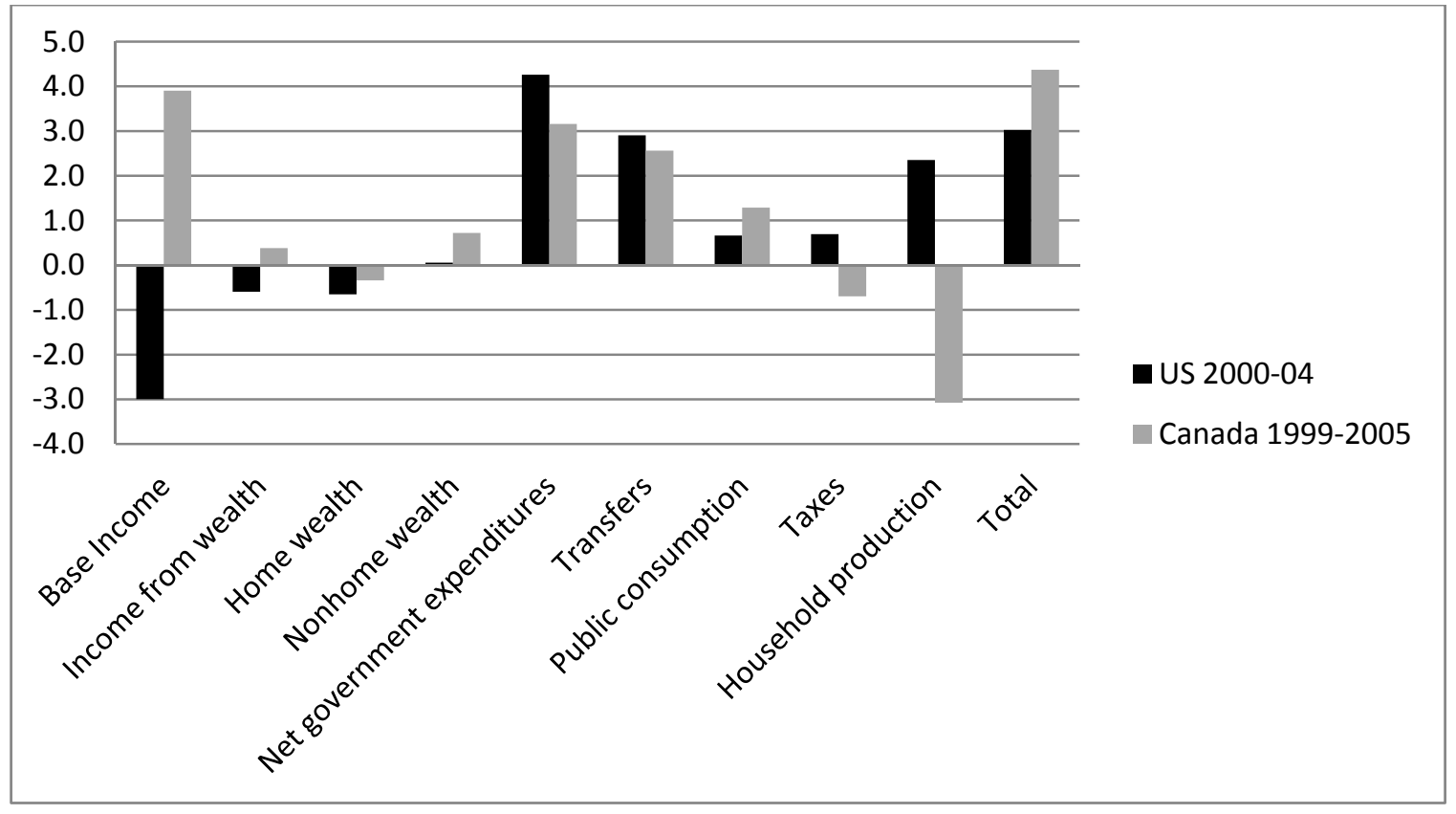


Figure 6a. Disparities between family types in LIMEW

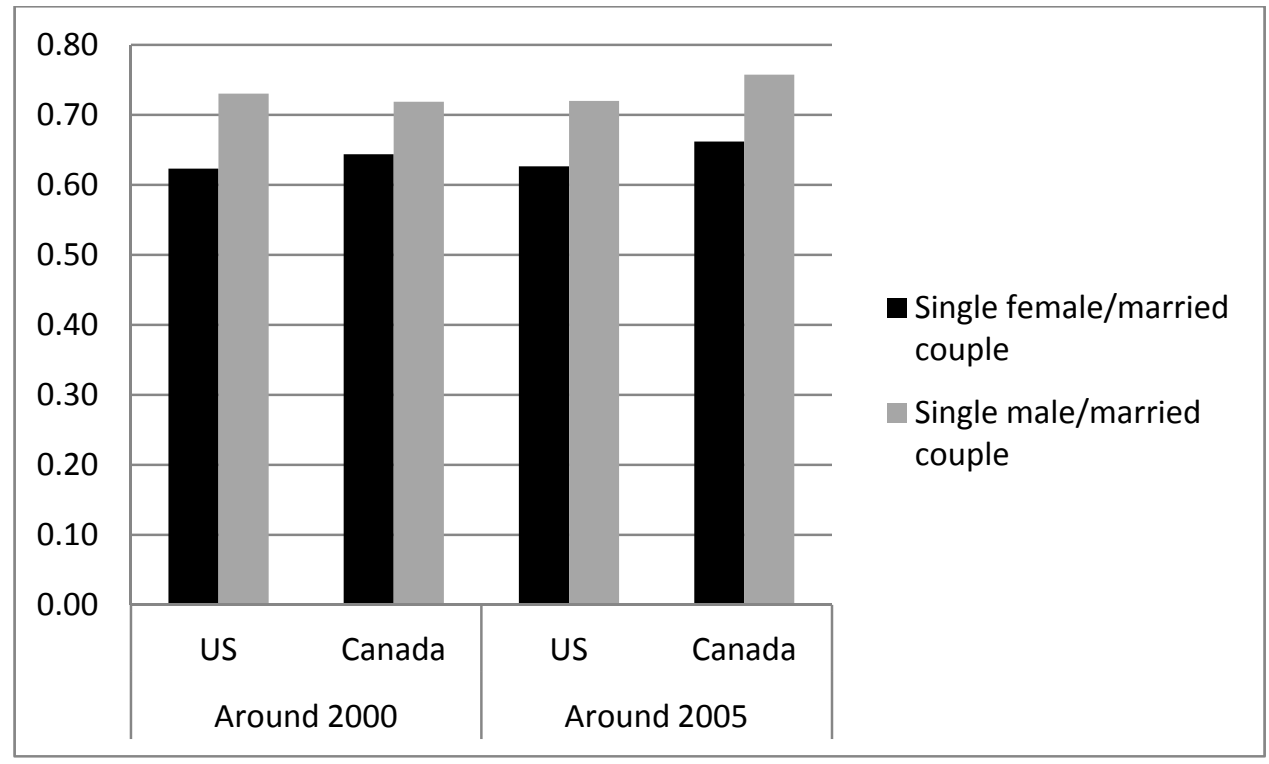

Figure 6b. Gaps between Canada and US in the disparities between single female-headed and married couple families by component

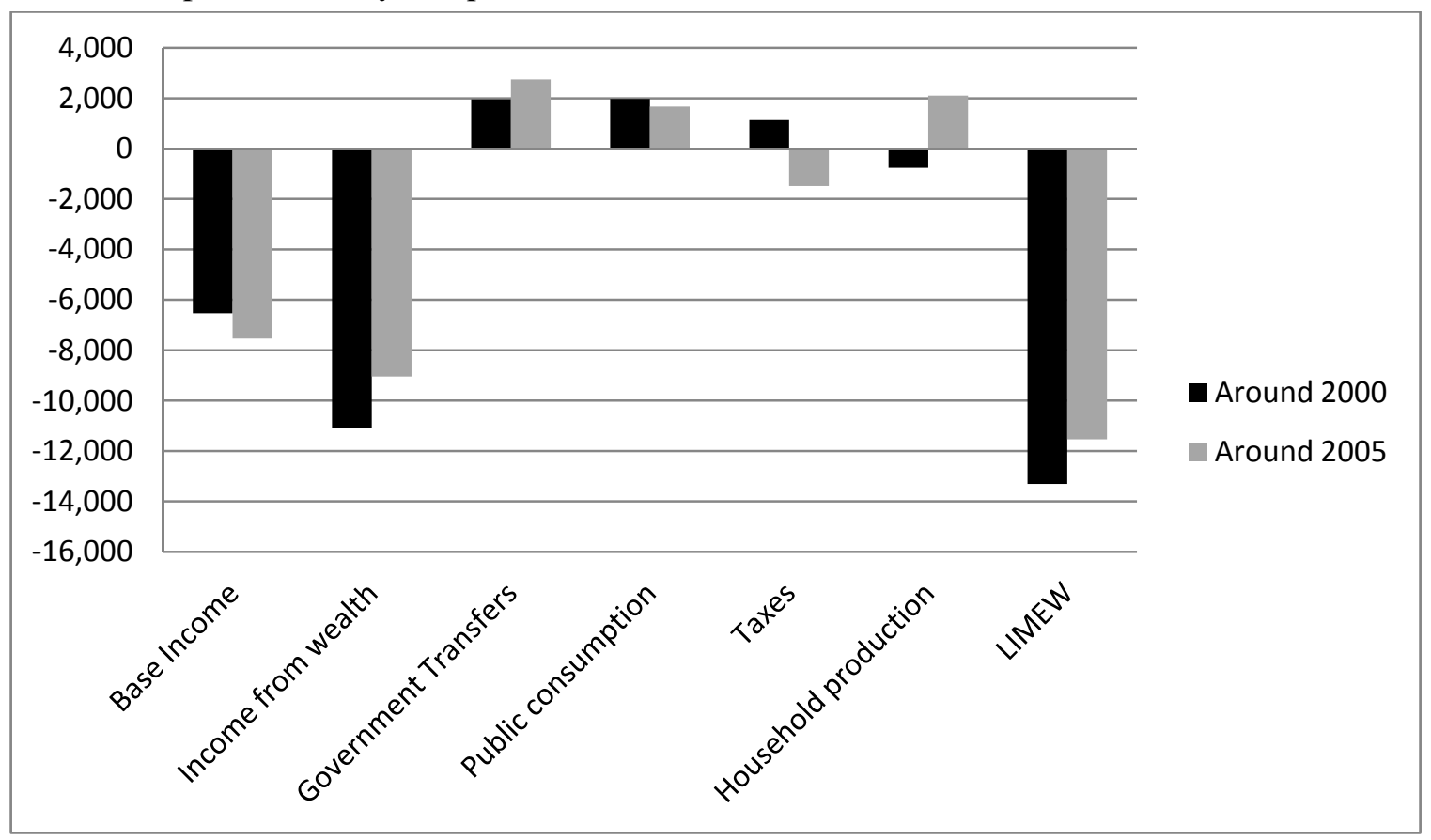


Figure 7a. Elderly to nonelderly disparity in LIMEW and MI

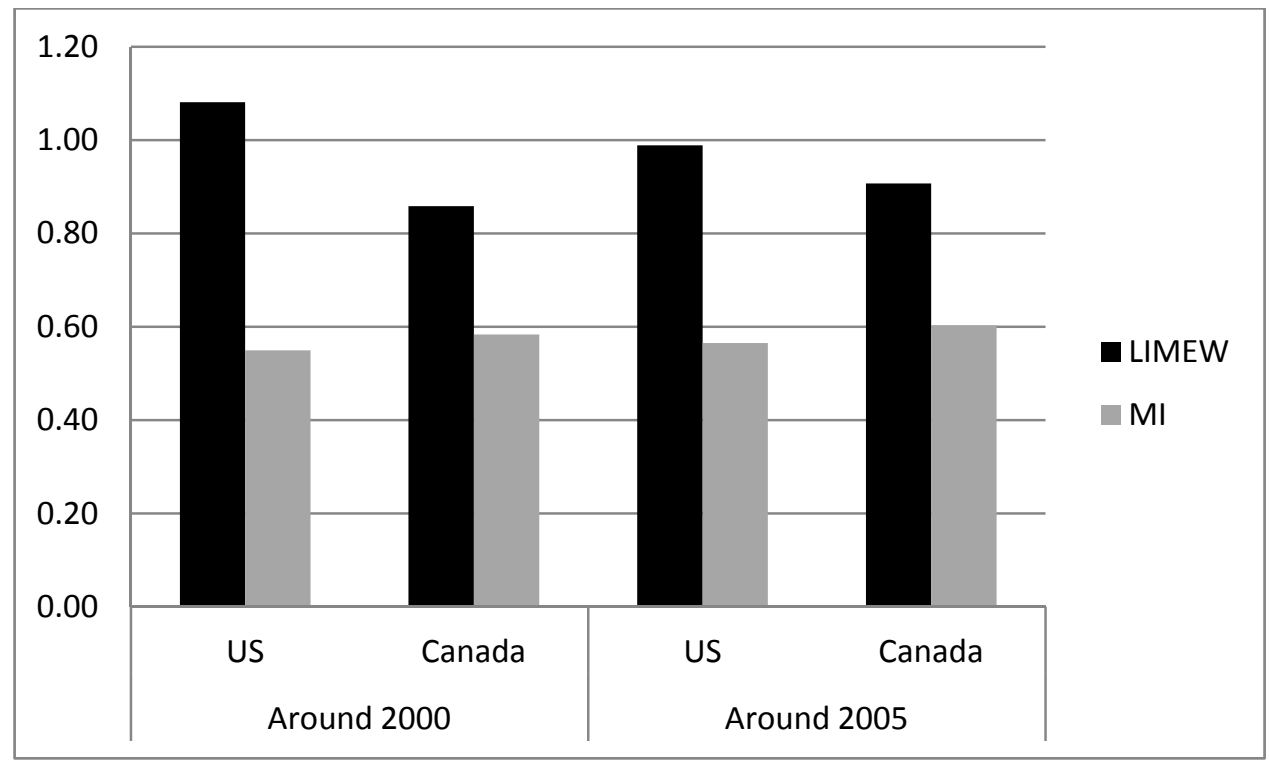

Figure 7b. Gaps between Canada and US in the disparities between elderly and nonelderly households by component

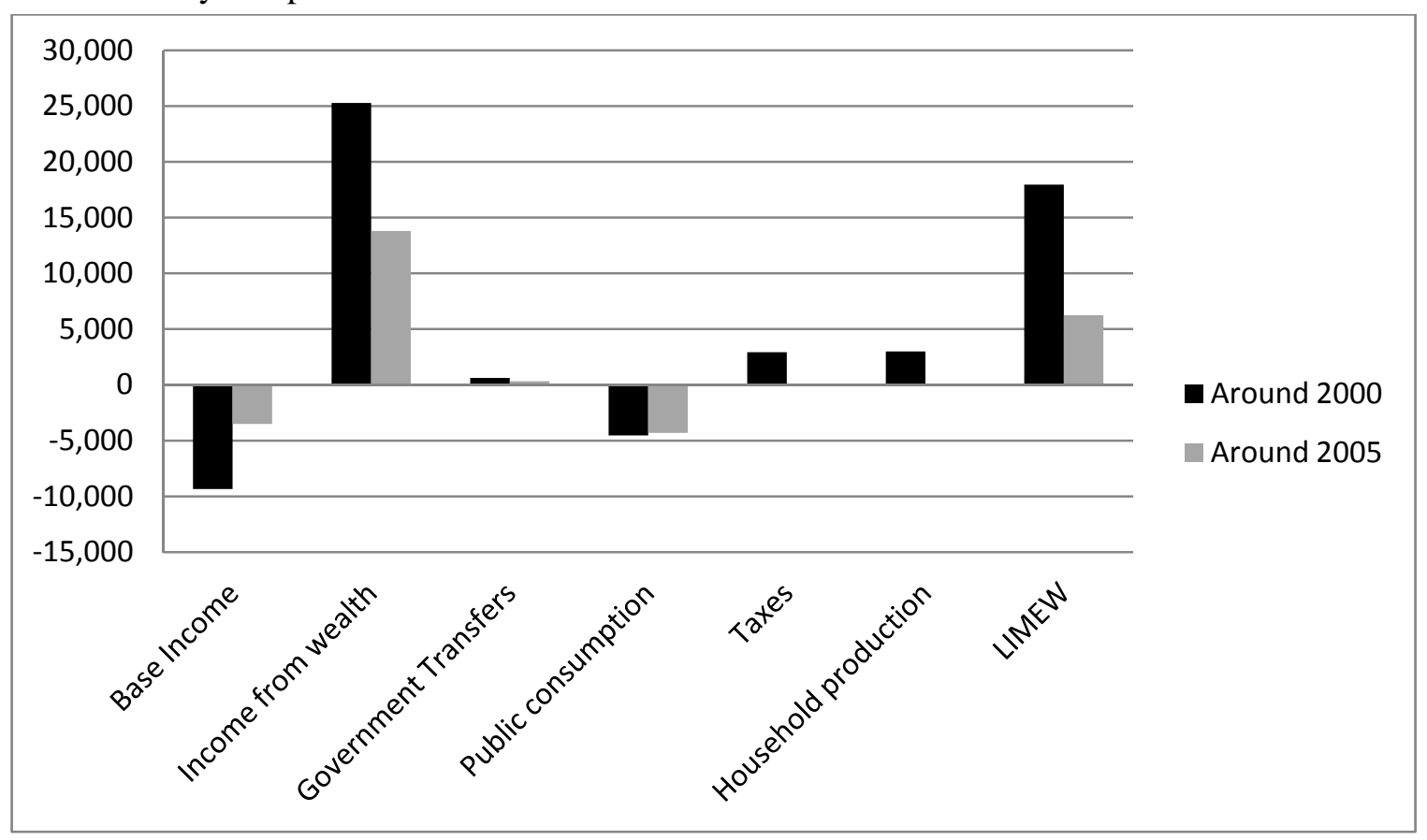


Figure 8a. Disparities by educational attainment in LIMEW

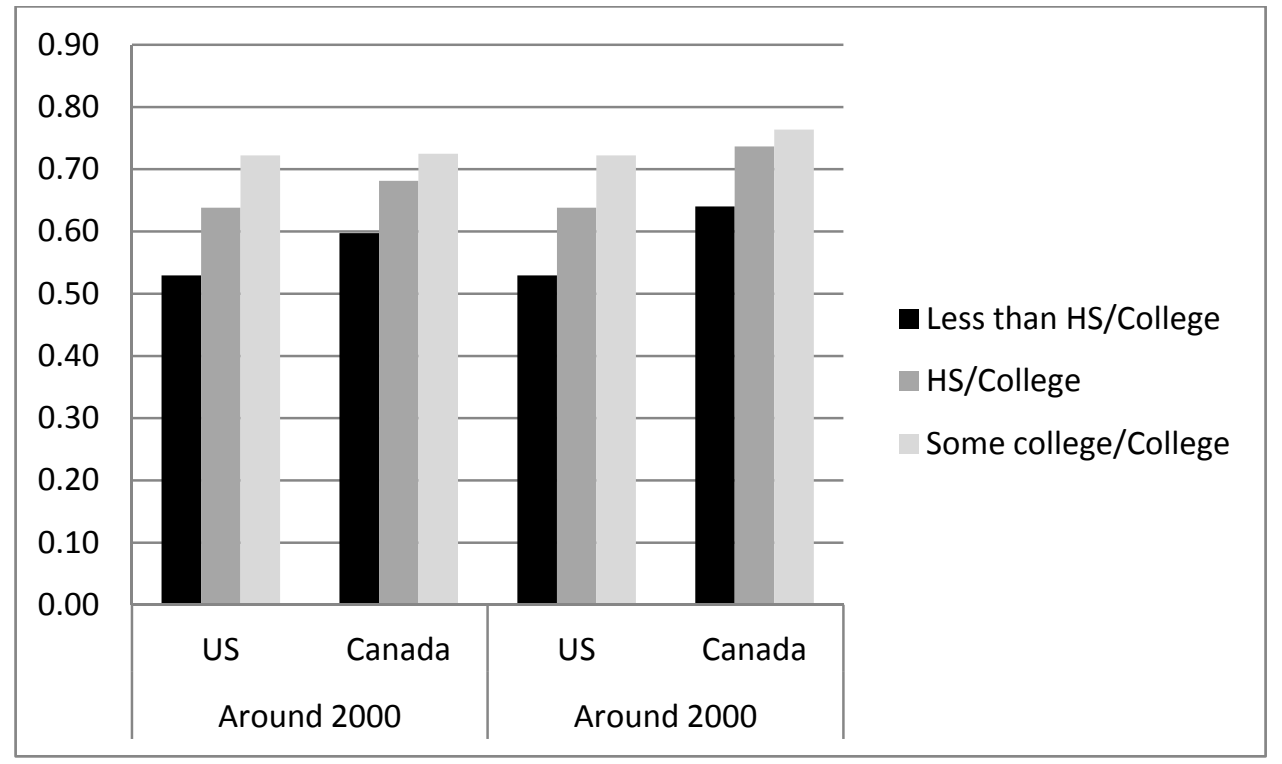

Figure $8 b$. The gap between Canada and US in LIMEW by component between high school and college graduates

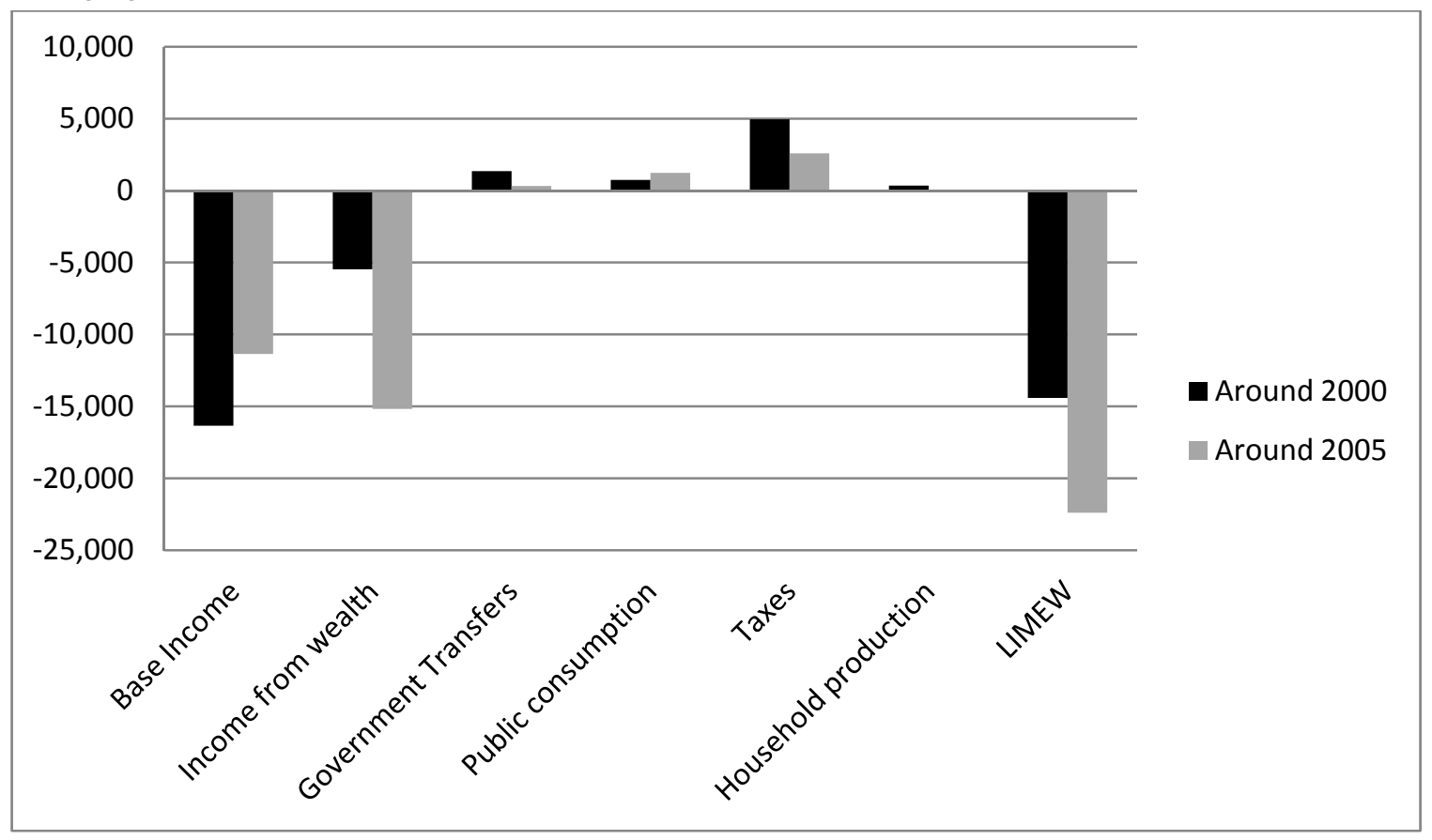


Figure 9. LIMEW by decile in Canada and the US

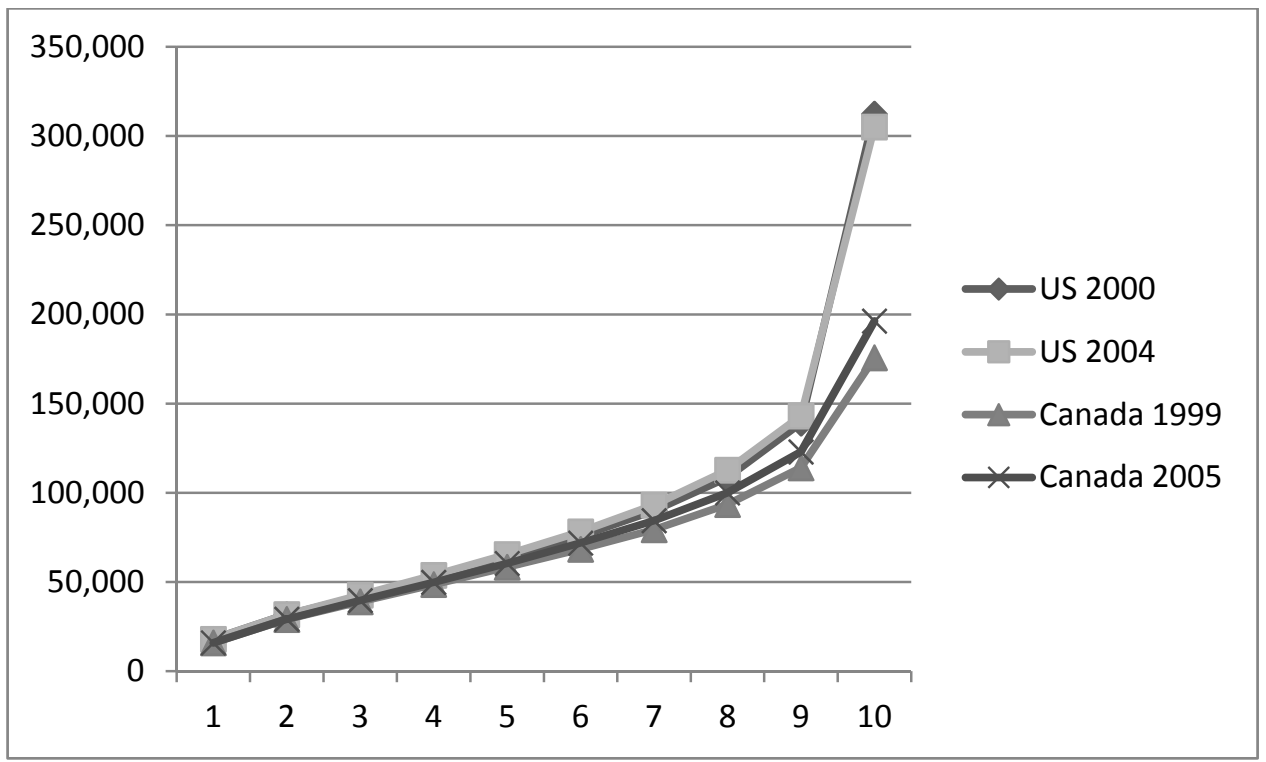




\section{APPENDIX: DATA SOURCES}

The information required to estimate the LIMEW is not available in a single household survey (see Table 1 for a listing of the components of the LIMEW). Therefore, it was necessary to create a synthetic microdata file for each benchmark year. At a very basic

level, our empirical strategy in estimating the LIMEW can be described as starting with a large microdata file with income and demographic characteristics, and then adding on the supplementary information, either via statistical matching or other imputation techniques, to estimate the various components of the LIMEW. The procedures for creating the files for the two countries are described below.

\section{The United States}

Our main data source is the public use data files developed by the US Bureau of the Census from the Current Population Survey's Annual Social and Economic Supplement (ASEC), which is the most comprehensive source of annual information regarding a number of key demographic characteristics (as of the survey year), household income, and receipt of noncash transfers (as of the previous year). Additional information required to construct the core synthetic file was obtained from the following nationally representative surveys via statistical matching with the Annual Demographic Survey (ADS): the 2001 and 2004 rounds of the Survey of Consumer Finances (SCF) that contains detailed information on household wealth, and the American Time Use Survey (ATUS) conducted in 2003 and 2004. The major steps involved in constructing the LIMEW by adding supplementary information are shown in Table A1. Each of the steps described in the table is discussed briefly below.

\section{Lines 11 through 13:}

Statistical matching with SCF was conducted to obtain the amounts of assets and liabilities for each household in the ASEC. Values of assets (other than homes) and liabilities were "aged" back from their 2001 to 2000 levels by deflating each asset and liability with their respective rate of return. Home values were deflated to the 2000 level by the percent change in the national median home price between the survey and previous year. Lifetime annuities (including annuitized payments on debts) were calculated based 
on the demographic information available in the ASEC (age, sex, and race of the head and spouse of wealth holding families), life expectancy tables (differentiated by age, sex, and race-obtained from the Statistical Abstract of the United States, various years), and long-term rates of return by asset type (see Table A2). The aggregate amount of imputed rent on owner-occupied housing (reported in the national accounts, NIPA Table 7.12, Line 209) was distributed among households according to the gross value of homes.

\section{Lines 14 through 18:}

All taxes, except consumption taxes, have imputed values in the ADS and were aligned with their NIPA counterparts by distributing for each tax the discrepancy between the NIPA and ASEC aggregate among households according to the share of each household in the ASEC aggregate. Consumption taxes were estimated by using the effective tax rates estimates by the Institute of Taxation and Economic Policy (ITEP). The average state tax rates are available for "General Sales-Individuals" and "Other Sales and Excise-Individuals” differentiated for households in each quintile of the household income distribution and for selected quintiles of the top distribution. To estimate the taxes paid by households in the ASEC, we assigned the tax rates estimated by the ITEP to households in the ASEC in the corresponding state and position in the household income distribution.

\section{Lines 19 through 20:}

Transfers for which actual or imputed amounts are reported in the ADS are aggregated across recipients and compared against the benchmarks. Any discrepancy between the ASEC total and the NIPA benchmark for a given transfer payment is distributed across recipients according to the distribution of that payment in the ADS. Transfers that are recorded in the ASEC have NIPA amounts that make up roughly 90 percent of all transfers reported in the NIPA Table 3.12 “Government social benefits.” Additional imputations were carried out for some noncash transfers (e.g., the nutritional program known as Women, Infants, and Children (WIC), payments to nonprofit organizations providing social benefits to households, etc.) reported in the national accounts, based on household/individual characteristics in the ASEC, and a variety of administrative sources. 


\section{Line 21:}

Estimates of public consumption by households were constructed in three steps: (1) obtaining total expenditures by function and level of government; (2) allocating total expenditures between the household sector and other sectors of the economy; and (3) distributing expenditures allocated to the household sector among households.

\section{Expenditure by Function and Level of Government.}

The expenditure category used here is government consumption expenditures and gross investment (the same as that on the product side of the NIPA). To group expenditures according to purpose, we adopted the functional classification in NIPA with minor modifications.

We distributed the NIPA aggregate of state and local expenditures for each function among the states using the interstate distribution of these expenditures in the Annual Survey of Government Finances (ASGF) or the Census of Governments conducted by the US Bureau of the Census. Care was taken to ensure that the expenditure concept and the groupings of the functions in the Census Bureau data conform as closely as possible to the NIPA expenditure and function concepts.

\section{Allocation of Expenditures to the Household Sector.}

We started by constructing a schema of detailed functions by level of government (federal versus state and local). ${ }^{26}$ Then, we grouped these functions into three categories. The first involved activities that do not expand the potential amenities available to the household sector. General public service, national defense, law courts, and prisons are prominent examples. The second category included functions that are assumed to expand amenities directly only to the household sector, such as income security, recreation, and culture.

The third category consisted of functions that can potentially serve both the household and non-household sectors, such as economic affairs, housing, and community services. Costs incurred in the performance of these functions are allocated to the household sector in accordance with the extent that they are "responsible" in generating 
such costs. Our judgment regarding the extent of responsibility is based, as much as possible, on the available empirical information. A prominent example of this type of function is highways (included under economic affairs), where approximately 60 percent of expenditures were estimated to occur on behalf of households.

Distribution of Allocated Expenditures among Households.

After determining government expenditures allocated to the household sector (i.e., “public consumption”) by function, we distributed them among households. We attempted to follow the same principles of direct usage and cost responsibility that were employed in splitting total government expenditures between the household and nonhousehold sectors. Two major categories of public consumption are distributed among households: those distributed equally across persons (such as public health and hospitals, police and fire) and those distributed according to household-level, or person-level, characteristics (such as elementary and secondary education, highways).

The second group of expenditures account for the bulk of public consumption (nearly three-quarters). The person-level or household-level characteristics used in the distribution procedures, and their corresponding functions, are listed below:

Amount and type of income: agriculture.

Type of income received (including receipt of noncash transfers): public housing, administrative costs of Medicare, disability, retirement income (Social Security), welfare and social services, and unemployment compensation.

Shares in consumption expenditures: energy, pollution control and abatement, postal service, liquor stores, water supply, sewerage and sanitation.

Enrollment in public educational institutions: education.

Patterns of vehicle ownership and transportation usage: transportation and parking.

Employment status: occupational safety and health.

Information on the type and amount of income, as well as the employment status of individuals, is obtained directly from the primary data file such as the Integrated 
Public Use Microdata Series (IPUMS) or ADS. All other characteristics were imputed to individuals or households in the primary sample from information gathered from external sources.

\section{Line 22:}

Hours of household production were obtained via a statistical match with the ATUS. We calculated the hourly wage rate for private household workers from the annual file that was created by merging the Current Population Survey's monthly outgoing rotations files. The wage rate was defined as usual weekly earnings divided by usual weekly hours of work. The variables required for constructing the performance index (educational attainment, time availability, and household income) were available directly in the ASEC.

\section{Canada}

Based on data availability, 1999 and 2005 were selected as benchmark years for the LIMEW for Canada. The sampling frame of the synthetic data files is the Survey of Labour and Income Dynamics (SLID). In addition to the variables included in the SLID, the synthetic data file also includes estimates of income from wealth, taxes, transfers, public consumption, and the value of household production.

The main steps involved in construction of the 1999 and 2005 files are shown in Table A3. The steps described in Lines 1-4 describe the calculation of base income that used the variables available in the SLID, with the exception of fringe benefits which are not included in the SLID. The 1999 and 2005 SLID questionnaire does ask its respondents if their employer offered them supplementary medical insurance, dental insurance, or life/disability insurance. However, these data are not included in the public use microdata files. Unpublished data was obtained from Statistics Canada via special request on the value of these benefits. The latter were assigned to persons based on the size of their workplace, and whether or not they are covered by a collective agreement. ${ }^{27}$

\footnotetext{
${ }^{27}$ The probability of receiving fringe benefits is estimated by workplace size and collective agreement coverage status based on the Workplace and Employee Survey. Benefits are then assigned to SLID workers
} 
The steps described in Lines 5 through 7 were carried out to obtain estimates of income from wealth. Data on assets and debts reported in the Survey of Financial Security (SFS) for 1999 and 2005 were transferred wealth to the SLID via statistical matching. In conjunction with the information already available in the SLID (age and sex) and external information (life expectancy, long-run rates of return on nonhome net worth $^{28}$, and aggregate imputed rent on owner-occupied housing), we calculated income from wealth. Statistical matching of wealth and the calculations for income from wealth was carried out to obtain the estimates of assets and liabilities for households in the SLID.

Lines 8 through 16 were carried out for creating the variables accounting for the flows of purchasing power between the households and government. They involve the estimation of government expenditures incurred on behalf of households - transfers and public consumption — and taxes paid by households. Estimates have been completed for both benchmark years.

Cash transfers from the government, such as Social Assistance, Old Age Security, Canada Pension Plan benefits, and Employment Insurance benefits, are identified in the SLID. As in the case of the US, we aligned the value of government transfers in our estimates to the benchmarks available from the national accounts. Income taxes and the employee portion of payroll taxes ${ }^{29}$ are provided in both years of the SLID.

Information on property taxes is drawn from the Survey of Household Spending (SHS), since it is not available in the SLID or the SFS. We calculated the average property tax rate by region in 2005 by dividing the total amount paid in property taxes by

on the basis of these probabilities. Each worker assigned benefits receives the same value of benefits, and non-workers and those not assigned benefits receive zero benefits.

${ }^{28}$ The categories included in the Canadian and American wealth surveys for nonhome wealth are broadly similar with the important exception of pension assets. In the American estimates, we include in the pension assets only the cash surrender value of defined-contribution pension plans. In contrast, in the Canadian estimates, we include, in addition, the imputed value of defined-benefit plans, the most common form of private pension coverage available to Canadian workers. For perfect comparability, we should have either included the value of defined-benefit plans in our American estimates or omitted their value in the Canadian estimates. However, it is not possible to identify which households have defined benefit plans and which have defined contribution plans in the SFS. The procedure used by Statistics Canada to impute the value of defined benefit plan is also not publicly available.

${ }^{29}$ Payroll taxes in Canada consist of the employee proportion of employment insurance (EI); Canadian Pension Plan or Quebec Pension Plan (CPP/QPP) (the Canadian equivalent of Social Security); and public health insurance premiums. 
households (from the SHS) by the total value of properties (from the SFS) in each region. In 1999, the SFS has a province variable so we calculated average property tax rates the same way, but by province instead of region.

Consumption taxes are not included in any of the surveys. In order to estimate consumption tax rates, we requested Statistics Canada to calculate the proportion of income spent on consumption taxes by provinces and disposable income deciles. Statistics Canada calculated this by using the Input-Output Commodity Tax Model associated with their Social Policy Simulation Database and Model (SPSD/M), a microsimulation model used for policy analysis. The commodity tax model calculates the amount households spend on commodity taxes by first calculating the effective tax rate for each tax type and then multiplying the effective tax rate by the amount spent on the category in the database (SPSD). As per our request, Statistics Canada calculated the average amount households spent on commodities taxes in 1999 and 2005, by disposable income (i.e., after income tax) decile and by province. We then divided these amounts by the average disposable income by deciles and provinces to get the ratio of average tax spent over average income. Then for each household, we multiplied this ratio of average tax spent (in their province and income decile) over average income (in their province and income decile) by household disposable income to obtain the total consumption tax paid by the household.

Estimates of public consumption were obtained using a procedure similar to that used for the US LIMEW. The summary of the allocation and distribution assumptions is provided in Table A4.

The value of household production is indicated in Line 17. Information on timeuse was obtained from the 1998 and 2005 rounds of the General Social Survey (GSS). The individuals in the SLID files were statistically matched to the individuals in the GSS to obtain the time spent on household production. 
Table A1 Construction of the 2000 and 2004 files, United States

\begin{tabular}{|c|c|c|}
\hline Line No & Component & Source \\
\hline 1 & Earnings & \multirow{7}{*}{ ASEC } \\
\hline 2 & Money income other than earnings & \\
\hline 3 & Property income & \\
\hline 4 & Private pensions & \\
\hline 5 & Government cash transfers & \\
\hline 6 & Other money income & \\
\hline 7 & Money income (MI): Sum of Lines 1 and 2 & \\
\hline 8 & \multicolumn{2}{|c|}{$\begin{array}{l}\text { Less: Property income (Line 3), Private pensions (Line 4) and } \\
\text { Government cash transfers (Line 5) }\end{array}$} \\
\hline 9 & Equals: Base money income & \\
\hline 10 & $\begin{array}{l}\text { Plus: Employer contributions for health } \\
\text { insurance }\end{array}$ & ASEC \\
\hline 11 & Plus: Income from wealth & \multirow{3}{*}{ Statistical matching of ASEC with SCF } \\
\hline 12 & Annuity from nonhome wealth & \\
\hline 13 & Imputed rent on owner-occupied housing & \\
\hline 14 & Less: Taxes & \\
\hline 15 & Income taxes & \multirow{3}{*}{ ASEC and NIPA } \\
\hline 16 & Payroll taxes & \\
\hline 17 & Property taxes & \\
\hline 18 & Consumption taxes & ASEC and estimates from ITEP \\
\hline 19 & Plus: Cash transfers & $\begin{array}{l}\text { Same as Line } 5 \text { above; and, NIPA for } \\
\text { relevant aggregates }\end{array}$ \\
\hline 20 & Plus: Noncash transfers & ASEC, administrative data and NIPA \\
\hline 21 & Plus: Public consumption & ASEC and others (see section A.4) \\
\hline 22 & Plus: Household production & Statistical matching of ASEC and ATUS \\
\hline 23 & Equals: LIMEW & \\
\hline
\end{tabular}

Notes: ASEC = Annual Social and Economic Supplement; SCF = Survey of Consumer Finances; NIPA = National Income and Product Accounts; ITEP = Institute for Taxation and Economic Policy; ATUS = American Time Use Survey. 
Table A2 Long-term average rates of return, United States (in percent)

\begin{tabular}{|l|c|c|c|}
\hline & Nominal & Real & Period \\
\hline Real estate and business & 6.96 & 2.63 & $1960-2007$ \\
\hline Liquid assets & 5.48 & 0.88 & $1965-2007$ \\
\hline Financial assets & 7.54 & 3.19 & $1960-2007$ \\
\hline Pension assets & 6.72 & 3.58 & $1986-2007$ \\
\hline Mortgage debt & 0.00 & -4.04 & $1960-2007$ \\
\hline Other debt & 0.00 & -4.04 & $1960-2007$ \\
\hline Inflation rate (CPI-U) & 4.21 & & $1960-2007$ \\
\hline
\end{tabular}

Notes:

Real rate of return $=(1+$ Nominal rate $) /(1+$ Inflation rate $)-1$

Real estate and business: Holding gains (taken from the Flow of Funds table R.100) divided by equity in non-corporate business (taken from the Flow of Funds table B.100).

Liquid assets: The weighted average of the rates of return on checking deposits and cash, time and saving deposits, and life insurance reserves. The weights are the proportion of these assets in their combined total (calculated from the Flow of Funds table B.100). The assumptions regarding the rates of return are: zero for checking deposits, the rate of return on a 1-month CD (taken from the table "H.15 Selected Interest Rates" published by the Federal Reserve and available at: http://www.federalreserve.gov/releases/h15/data.htm) for time and saving deposits, and one plus the inflation rate for life insurance reserves.

Financial assets: The weighted average of the rates of return on open market paper, Treasury securities, municipal securities, corporate and foreign bonds, corporate equities, and mutual fund shares. The weights are the proportion of these assets in total financial assets held by the household sector (calculated from the Flow of Funds table B.100). The assumption regarding the rate of return on open market paper is that it equals the rate of return on 1-month Finance paper (taken from the table "H.15 Selected Interest Rates" published by the Federal Reserve and available at: http://www.federalreserve.gov/releases/h15/data.htm). The data for the rates of return on other assets are taken from the Economic Report of the President 2005, Table B.73. The assumptions regarding Treasury securities, municipal securities, corporate and foreign bonds, and corporate equities are, respectively, average of Treasury security yields, high-grade municipal bond yield, average of corporate bond yields, and annual percent change in the S\&P 500 index. Mutual fund shares are assumed to earn a rate of return equal to the weighted average of the rates of return on open market paper, Treasury securities, municipal securities, corporate and foreign bonds and corporate equities. The weights are the proportions of these assets in the total financial assets of mutual funds (calculated from the Flow of Funds table L.123).

Pension assets: Net acquisition of financial assets (taken from the Flow of Funds table F.119c) divided by total financial assets of private defined-contribution plans (taken from the Flow of Funds table L.119c).

Inflation rate: Calculated from the CPI-U published by Bureau of Labor Statistics. 
Table A3 Construction of the 1999 and 2005 files, Canada

\begin{tabular}{|r|l|l|}
\hline Line No. & \multicolumn{1}{|c|}{ Component } & \\
\hline 1 & Base Income = sum of lines 2-4 & \\
\hline 2 & Earnings & SLID \\
\hline 3 & Fringe benefits & Unpublished Statistics Canada data \\
\hline 4 & Money income other than earnings and government transfers & SLID \\
\hline 5 & Income from wealth = sum of lines 6-7 & \\
\hline 6 & Annuity from nonhome wealth & Statistical matching of SLID and SFS \\
\hline 7 & Net imputed rent on housing & Statistical matching of SLID and SFS; aligned with SNA aggregate \\
\hline 8 & Government transfers & SLID data aligned with SNA aggregate \\
\hline 9 & Public consumption & SLID, SNA, and others \\
\hline 10 & Taxes & \\
\hline 11 & Federal income tax & SLID data aligned with SNA aggregate \\
\hline 12 & Provincial income tax & SLID data aligned with SNA aggregate \\
\hline 13 & Payroll tax & SLID data aligned with SNA aggregate \\
\hline 14 & Consumption tax & Statistics Canada Input-Output Commodity Tax Model \\
\hline 15 & Property tax & Tax rates from SHS, home ownership from SLID \\
\hline 16 & Net Government Expenditure = lines $8+9-10$ & \\
\hline 17 & Household production & Statistical matching of SLID and GSS, other \\
\hline 18 & LiMEW = lines $1+5+16+17$ & \\
\hline & & \\
\hline
\end{tabular}

Notes:

SLID = Survey of Labour and Income Dynamics

SFS = Survey of Financial Security

SHS $=$ Survey of Household Spending

SNA $=$ System of National Accounts

GSS $=$ General Social Survey 
Table A4 Allocation and distribution of government consumption and gross investment expenditures, Canada

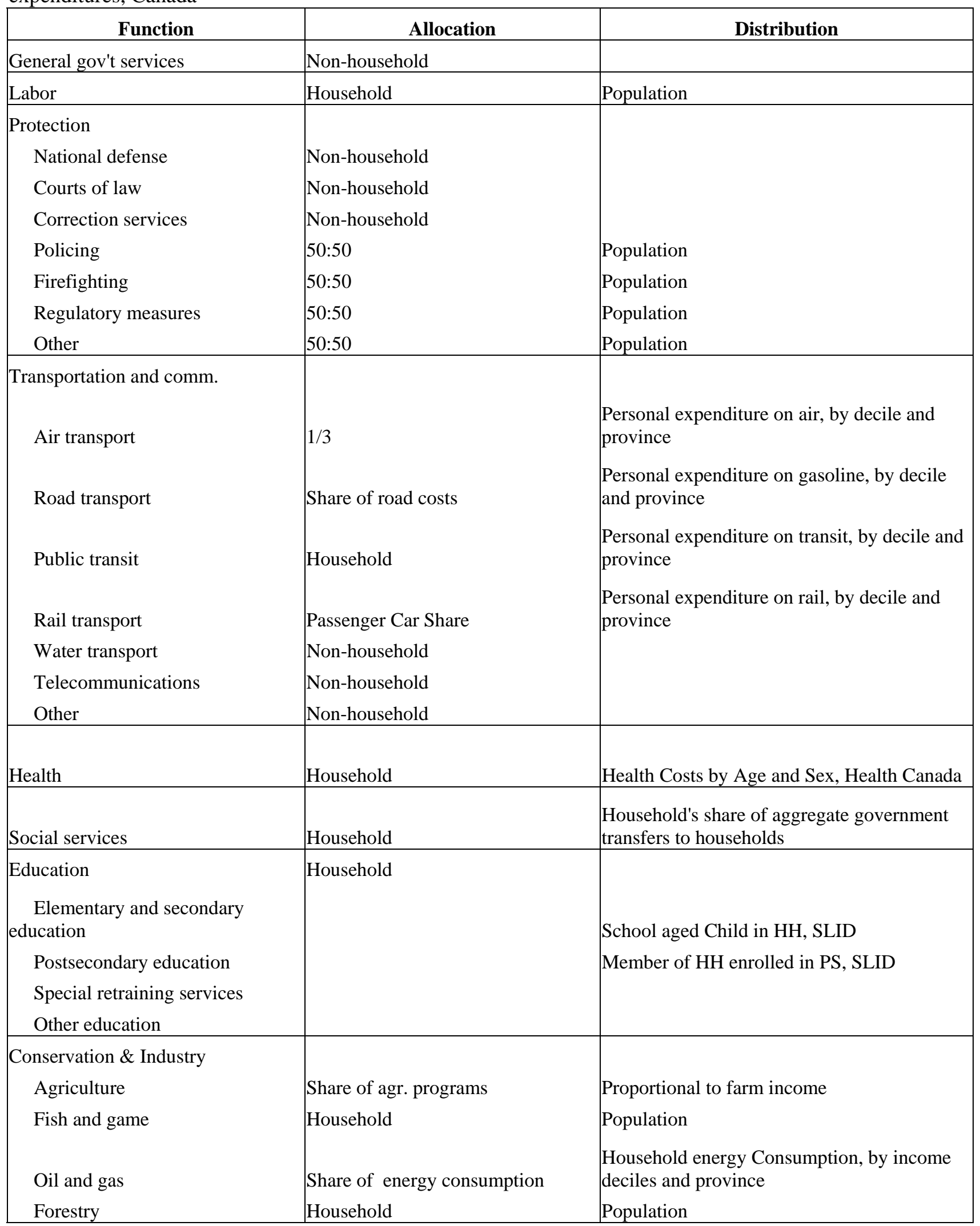




\begin{tabular}{|l|l|l|}
\hline \multicolumn{1}{|c|}{ Function } & \multicolumn{1}{|c|}{ Allocation } & \multicolumn{1}{c|}{ Distribution } \\
\hline Mining & Non-household & Hater power \\
$\begin{array}{c}\text { Tourism promotion } \\
\text { Trade and industry } \\
\text { Other }\end{array}$ & $\begin{array}{l}\text { Share of energy consumption } \\
\text { Non-household } \\
\text { Non-household } \\
\text { deciles and province }\end{array}$ & \\
\hline $\begin{array}{l}\text { Environment } \\
\text { Water } \\
\text { Pollution control } \\
\text { Other }\end{array}$ & $\begin{array}{l}\text { Water use } \\
\text { Share of GHG emission }\end{array}$ & \\
\hline Recreation and culture & Share of Waste Disposal & Ecological footprint by decile, CCPA \\
\hline Housing & Household & By household personal expenditure on \\
\hline Foreign affairs & Household & Receiving Gov't Reduced Rent \\
\hline Regional development & Non-household & \\
\hline Research establishments & Non-household & \\
\hline Transfers & Non-household & \\
\hline Debt charges & & \\
\hline Other expenditures & n/a & \\
\hline
\end{tabular}

